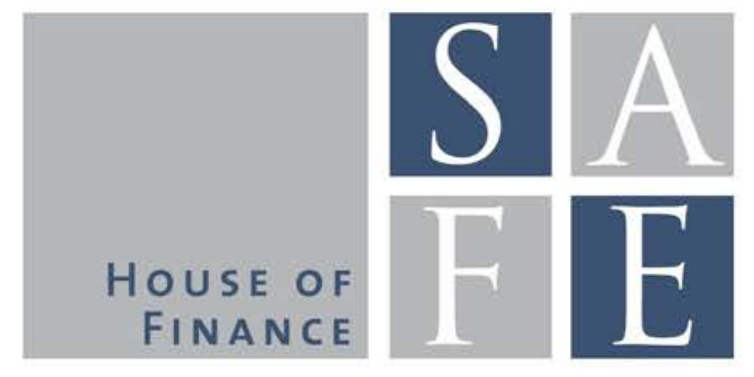

WORKING PAPER SERIES

Axel H. Börsch-Supan - Klaus Härtl - Duarte N. Leite Alexander Ludwig

\title{
Endogenous Retirement Behavior of Heterogeneous Households Under Pension Reforms
}

SAFE Working Paper No. 221

SAFE I Sustainable Architecture for Finance in Europe A cooperation of the Center for Financial Studies and Goethe University Frankfurt 


\title{
Endogenous Retirement Behavior of Heterogeneous Households Under Pension Reforms
}

\author{
Axel Börsch-Supan ${ }^{a, b, c}$, Klaus Härtl ${ }^{a, c}$, Duarte N. Leite ${ }^{a, e}$, Alexander Ludwig ${ }^{a, d}$ \\ ${ }^{a}$ Munich Center for the Economics of Aging at the Max-Planck-Institute for Social Law and Social Policy \\ ${ }^{b}$ National Bureau of Economic Research (NBER) \\ ${ }^{c}$ Technical University of Munich (TUM) \\ ${ }^{d}$ SAFE, Goethe University Frankfurt \\ ${ }^{e}$ Center for Economics and Finance at the University of Porto (CEF.UP)
}

This draft: 25 April 2018

\begin{abstract}
We propose a unified framework to measure the effects of different reforms of the pension system on retirement ages and macroeconomic indicators in the face of demographic change. A rich overlapping generations (OLG) model is built and endogenous retirement decisions are explicitly modeled within a public pension system. Heterogeneity with respect to consumption preferences, wage profiles, and survival rates is embedded in the model. Besides the expected direct effects of these reforms on the behavior of households, we observe that feedback effects do occur. Results suggest that individual retirement decisions are strongly influenced by numerous incentives produced by the pension system and macroeconomic variables, such as the statutory eligibility age, adjustment rates, the presence of a replacement rate, and interest rates. Those decisions, in turn, have several impacts on the macro-economy which can create feedback cycles working through equilibrium effects on interest rates and wages. Taken together, these reform scenarios have strong implications for the sustainability of pension systems. Because of the rich nature of our unified model framework, we are able to rank the reform proposals according to several individual and macroeconomic measures, thereby providing important support for policy recommendations on pension systems.
\end{abstract}

\section{Keywords:}

Population aging, pension reform, social security, life-cycle behavior, labor supply, retirement age, welfare

JEL classification: C68, D91, E17, H55, J11, J26

Acknowledgements: We thank discussants and participants at the 5th International Workshop on the SocioEconomics of Ageing, the European Economics Association meeting 2017, the Spring Meeting of Young Economists 2017, and the 10th BiGSEM Doctoral Workshop on Economic Theory 2015 for their helpful comments on earlier versions. The usual disclaimer applies. 


\section{Introduction}

Pension reforms are a subject of controversy in many countries as they affect all sectors of society and are always at the center of public debate. In Europe, where the number of retirees per worker will continue increasing until about 2050, the ghost of unsustainability haunts public pay-as-yougo (PAYG) systems. It is feared that decreasing replacement rates or exploding contribution rates will lead to old-age poverty or disincentives in labor supply at younger ages. Furthermore, when it comes to the area of sustainability debate, fierce arguments emerge which point out both how to establish a new framework and avoid the foreseeable crash of the system and how to balance social expectations regarding retirement, income stability and future well-being. The pressing demographic transition and the negative effects of early retirement urged countries to take reforms that could no longer wait to be implemented, especially given the risk of unsustainability and the financial crisis that has undermined the budgets of countries in the last decade. Facing this challenge, numerous reforms have been put forward by policy makers to promote more active aging and a longer working life (Graf, et al., 2011; Börsch-Supan, 2007; Huber, et al., 2013; Sonnet, et al., 2014; Börsch-Supan, et al., 2017c). Such reforms have include increasing the statutory eligibility age in Germany or Italy (Börsch-Supan, 2007; Boeri, et al., 2016), the introduction of flexible retirement mechanisms in Norway and the UK (Börsch-Supan, et al., 2017a), and even profound changes in the main framework of the pension system (Palmer, 2000; Börsch-Supan, 2005). All of these reforms must be evaluated as individuals adapt to the new environment and possibly re-evaluate their life-cycle decisions. Even when direct incentive effects of reforms are taken into account, evaluations still sometimes lack possible backlash effects (Börsch-Supan, et al., 2014). For some reforms, these repercussions may be even stronger than the direct incentive effects (Eisensee, 2006).

There is a long and rich literature that examines endogenous behavior of households. Studies have shown that wealth and financial incentives have a great impact on retirement decisions (French, 2005; Chan \& Stevens, 2008) as well as on the household composition and income status of individuals (Coile, 2004; van der Klaauw \& Wolpin, 2008; Gustman \& Steinmeier, 2004; Fuster, et al., 2003). The design of pension systems is of great importance for determining the impact on retirement behavior because individuals sometimes react strongly or weakly to changes in incentives and in the framework of pension systems (Gustman \& Steinmeier, 2005; Duggan, et al., 2007; Kotlikoff, et al., 2007; Börsch-Supan \& Schnabel, 1998; Gruber \& Wise, 1999; BörschSupan, et al., 2017b).

In addition to these perspectives, some branches of literature attempt to look at households' selfcontrol problems, which affect their own decisions. These studies assume that households plan 
according to the life-cycle model but then fail to execute their plans, e.g. by procrastinating on the decision to set up and pay into a retirement savings account. Consumption and saving decisions are deeply affected by how households perceive and react to their own expectations (Angeletos, et al., 2001; Laibson, 1998). The impact on consumption and savings will deeply influence future retirement decisions and reactions to pension reforms, making this literature relevant for future understanding of pension reforms. An emerging branch of literature has given first steps on these issues (Diamond \& Köszegi, 2003; Findley \& Caliendo, 2015; Thanopoulos \& Kumru, 2008; Börsch-Supan, et al., 2018). In this paper we stick to the more classical approach as we want to disentangle the effects of several different pension reforms on the behavior of households and the impacts on the economy with a clean view of the channels involved, which would not be as clear if we were to introduce failures in the behavior of households.

This paper combines the lines of research on pension reforms, aging, and its macroeconomic implications. It sets a base for comparison of different reforms that have been recently proposed by the literature (Börsch-Supan, 2007; Gustman \& Steinmeier, 2005) and evaluates the endogenous reactions of households, which may dampen the intended outcomes of each reform, under a benchmark macroeconomic regime. These general effects are then examined on a deeper level when simulated under different extreme macroeconomic regimes. This allows us to draw conclusions regarding the effectiveness of such reforms when the macroeconomic environment changes. Outcomes differ if an economy is facing growth stagnation, or is instead under a lowinterest-rate regime which hinders savings, and hence, capital accumulation. We build a rich OLG model of the Auerbach and Kotlikoff type (Auerbach \& Kotlikoff, 1987) and quantify the effects of pension reforms on retirement decisions, taking into account demographic change and macroeconomic feedback cycles. We study incentives for retirement by focusing on the pension system: the model incorporates a PAYG system that connects individual contributions to social security and to benefits when retired (point system), which is partially or fully implemented in countries like France, Germany, and Norway (Social Security Administration, 2014). We assume that an earnings test is in place, meaning households leave the labor market at the time of claiming pension benefits.

Our model shares features with many recent papers, such as Sánchez-Martín (2010) and Fehr et al. (2012), but it differs by extending the reform settings in a more comprehensive way and by analyzing a number of new reform scenarios, enabling us to provide comparable outcomes from different reform proposals that have emerged in the literature. As a central contribution of this study, our model allows for a unified framework to compare different reform proposals and give valuable policy recommendations. In the literature, studies tend to look only at a specific reform 
(e.g. increase in statutory eligibility age) or combine initial reforms with supplementary ones without exploring the individual effects of each one. We, in contrast, separately examine every reform using the same framework. Under this approach, the isolated effects of reforms can be scrutinized and outcomes are not mixed up. Secondly, we compare a set of newly proposed reforms and evaluate them. This provides the literature with an extended analysis of the effects of the new solutions on the sustainability of pension systems and the endogenous effects that could be expected from each one.

Parallel to existing literature (Sánchez-Martín, 2010; Catalan, et al., 2010; Fehr, et al., 2012), we start by setting a benchmark scenario with a statutory eligibility age of 65 . We add to the model working costs which not only mimic commuting time to work but also other costs associated with declining health of workers. These costs may influence labor decisions and are not always introduced in these types of models. We introduce heterogeneity with respect to individual consumption preferences, wages, and survival rates by defining three equally large groups of individuals. These dimensions lead to interesting insights regarding endogenous retirement decisions and distributional effects of pension reforms, such as lower retirement ages for agents with low consumption preferences, as well as unequal effects of reforms between skill groups with respect to welfare.

In our baseline results, agents choose early retirement: during the given age interval of 60-72, agents retire between the ages of 60 and 65 . This mimics most pension systems that currently produce incentives for early retirement, which is mainly due to low actuarial adjustments before (after) the statutory eligibility age (Börsch-Supan, 2004; Werding, 2007; Gasche, 2012). As mentioned above, all further pension reforms are discussed, simulated and compared to this baseline scenario.

As a first reform, we simulate an increase of the statutory retirement age (SRA) from 65 to 67, which has already been introduced in several countries such as France, Germany, the UK, and others (Social Security Administration, 2014). Our results lead to the same increase in the labor force participation among older workers as observed empirically in Hanel and Riphan (2012) and Blundell and Emmerson (2007). However, actual retirement ages might not react fully to the increase in the statutory eligibility age. Still, agents work longer which takes pressure from the pension system's budget constraint and leads to beneficial effects for the PAYG pension system, which allows for lower contributions and higher pension levels. In terms of welfare measures, households are better off in this case than in the baseline scenario. Positive welfare consequences for increasing statutory retirement ages are in agreement with the literature (Beetsma, et al., 2003; Kotlikoff, et al., 2007; Catalan, et al., 2010). However, reform success turns out to be only 
temporary until the previous imbalances, which were controlled a decade before, emerge again since life expectancy is persistently increasing. That is why an increase in the statutory eligibility age today to 67 would lead, in about a decade, to the same problems currently being faced by the pension system. A way to prevent a repetition of this political discussion every decade is proposed by Börsch-Supan (Börsch-Supan, 2007). This proposal suggests that the connection between the statutory eligibility age and the increase in life expectancy is automatic. We model this reform in a second scenario and find very beneficial effects on contribution rates and welfare.

We further simulate a third scenario with actuarial neutral adjustment rates before and after the statutory eligibility age. In this case, agents work longer, removing pressure from the pension system's budget. This confirms previous findings in the literature. We extend these findings in a dynamic model, which shows that high adjustment rates do not always imply high retirement ages. In many cases retirement still occurs before the statutory eligibility age. Due to heterogeneity between groups, we observe that lower skilled groups are the ones who react the strongest. In terms of welfare measures, households are better off when actuarial neutral adjustment rates are added in the previous scenario.

In contrast to these findings, we simulate a fourth reform which refers to policy proposals that emerge, usually during election debates, and try to pose more weight on the well-being of older individuals and the challenges of old-age poverty: the political supporters of this reform proposal want to hold the replacement rate constant. Accordingly, the evolution of the replacement rate is not connected to developments in wages and the ratio of retirees to contributors anymore. We conclude that it leads to a 7.5 percentage raise in the contribution rate and households work less due to the inflated size of the pension system.

In order to state a point regarding the effects of the prevailing macroeconomic regime on the performance and impacts of each reform, we define two different macroeconomic regimes. Since the last financial crisis, interest rates have been low for a long period of time; therefore, we define a first regime where interest rates are set to be much lower than in the benchmark regime. We conclude that under such macroeconomic conditions, the pension system still becomes more sustainable than in the baseline scenario because of later retirement decisions from individuals. The second regime simulates a lower technological growth in the economy that also corresponds to a scenario of low economic growth. Under this regime, the effects of each reform are similar to the ones observed under the benchmark regime of high technological growth.

The paper is structured as follows: Section 2 introduces the model and all its modules. The methodological approach, including calibration, is described in Section 3. An analysis of the 
different effects of each reform are shown and discussed in Section 4. In Section 5, the performance of reforms under different macroeconomic regimes is tested. Section 6 concludes.

\section{Endogenous retirement decision model}

We extend the OLG model of the Auerbach and Kotlikoff type in several dimensions: we add a model of an earnings-related PAYG public pension scheme which combines aspects of a defined contribution system with those of defined benefits. Accordingly, a "replacement rate" is introduced in the public pension scheme. We allow for a discrete endogenous choice on retirement in addition to the continuous leisure/work and consumption/saving trade-offs. Furthermore, households differ in consumption preferences, wage profiles, and survival rates.

\subsection{Household problem}

There are $k=3$ different types of perfectly foresighted households at every point in time $t$ with age $j$ (heterogeneous agent setting). Each $k$-group has a population size equal to $1 / k$ of the total population at each time, $t$. It is assumed that they live up to a maximum age of $J$ years. Households have preferences over consumption and leisure. Accordingly, household $k$ receives utility from consumption and leisure as given by the following CES-type per-period utility function

$$
u^{k}\left(c_{t, j}^{k}, l_{t, j}^{k}\right)=\frac{1}{1-\theta}\left[\left(c_{t, j}^{k}\right)^{\phi_{j}}\left(l_{t, j}^{k}\right)^{1-\phi_{j}}\right]^{1-\theta} .
$$

$u^{k}$ is twice continuously differentiable, strictly increasing in consumption and leisure, and strictly concave. $\phi_{j}$ denotes the utility weight of consumption versus leisure and it is age-dependent. Risk aversion is described by the parameter, $\theta$, and a von Neumann-Morgenstern (VNM) expected utility maximization program over the entire life-cycle.

Leisure is time endowment (normalized to one) less hours worked, $h_{t, j}^{k}$. Additionally, a time cost $\vartheta\left(h_{t, j}^{k}\right)$ to take up work (also measured in hours) is introduced:

$$
l_{t, j}^{k}=1-h_{t, j}^{k}-\vartheta\left(h_{t, j}^{k}\right)
$$

Time costs $\vartheta\left(h_{t, j}^{k}\right)$ are present when households work and mimic the effect of declining health on the disutility of work (Börsch-Supan \& Stahl, 1991). This effect may be non-linear, increasing with the number of hours worked. The cost function is given by 


$$
\vartheta\left(h_{t, j}^{k}\right)=\chi_{\mathrm{j}}\left(1-\frac{1}{\left(1+h_{t, j}^{k}\right)^{\xi}}\right),
$$

where $\chi_{\mathbf{j}}$ is the age-dependent time costs of disutility of work and health decline. We assume that these time costs are, at the age of 80 , equal to $27 \%$ of the total available unit of time.

Each household $k$ maximizes utility

$$
\max \sum_{j=0}^{J} \beta^{j} \pi_{t, j}^{k} u^{k}\left(c_{t, j}^{k}, l_{t, j}^{k}\right)
$$

where $\beta^{j}$ is the discount factor and $\pi_{t, j}^{k}=\prod_{u=0}^{j} \varphi_{t, j}^{k}$ is the type-dependent (unconditional) survival probability. $\varphi_{t, j}^{k}$ is the corresponding conditional survival probability. Thus, households have uncertainty about the time of death and, therefore, have their life expectancy determined by the introduction of survival rates, which allows them to account for the probability of dying before reaching age $J$. We do not include intended bequests in our model and assume that accidental bequests resulting from premature death are taxed away by the government at a confiscatory rate and used for otherwise neutral government consumption.

Wages depend on age and household type,

$$
w_{t, j}^{k}=w_{t} \varepsilon_{j}^{k}
$$

where $\varepsilon_{j}^{k}$ generates age and type specific wage profiles.

The budget constraint is given by

$$
a_{t+1, j+1}^{k}=a_{t, j}^{k}\left(1+r_{t}\right)+h_{t, j}^{k} w_{t, j}^{k}\left(1-\tau_{t}\right)+p_{t, j}^{k}-c_{t, j}^{k}
$$

with

$$
0 \leq h_{t, j}^{k} \leq 1-\vartheta\left(h_{t, j}^{k}\right) \text { and } c_{t, j}^{k}>0
$$

$p_{t, j}^{k}$ are individual pension benefits (see below) and $a_{t, j}^{k}$ denotes assets. $\tau_{t}$ is the contribution rate of the public pension system.

\subsection{The public pension system}


The PAYG pension system is earnings-related and links individual past contributions to future pension benefits (pension points system). A point system allows one to relate individual benefits to the number of years contributed to the system and the relative earnings position compared to the economy's average. As a result, households understand the link between contributions and later pension benefits. Still, there is crowding out of private savings due to enforced contributions to the PAYG pension system.

Furthermore, we introduce a hybrid DB/DC-PAYG system which works as a balancing mechanism that moderates the negative impacts of population aging between different generations. A pension system of the defined benefit (DB) type means that a cohort of retirees is promised a pension benefit, $p_{t, j}^{k}$, which is typically defined by a replacement rate that is independent from the demographic and macroeconomic environment. The contribution rate to the system must then be adjusted to keep the PAYG system balanced. This set-up puts the highest burden on the young (working generation) since the contribution rate has to adjust in order to balance the pension budget equation (see 2.8). It is also possible to define the PAYG system as the defined contribution (DC) type. In this case, the pension system fixes the contribution rate for a cohort of workers. Therefore, the replacement rate reacts passively to developments in demography and employment. The DC system protects the younger generation from increases in the contribution rate, but population aging will make the older generation worse off by reducing their benefits in proportion to the decline in the system's dependency ratio. The aforementioned mechanism balances the burden of demographic change between different generations. Accordingly, the contribution rate to the pension system has to adjust less in times of population aging since the adjustment rate automatically scales down individual pension payments. An example of such a mechanism in the framework of earnings-related public PAYG pensions is the introduction of a "sustainability factor” in Germany (Börsch-Supan \& Wilke, 2005). It introduces DC elements into a pension system that remains framed as a DB system in order to appeal to voters' preferences.

The yearly pension budget equation is assumed to be balanced and given by

$$
\tau_{t} w_{t} \sum_{k=1}^{K} \sum_{j=1}^{R_{t}^{k}} \varepsilon_{j}^{k} h_{t, j}^{k} N_{t, j}^{k}=\sum_{k=1}^{K} \sum_{R_{t}^{k}+1}^{J} p_{t, j}^{k} N_{t, j}^{k}
$$

with individual pension benefits, $p_{t, j}^{k}$,given by

$$
p_{t, j}^{k}=\gamma_{t, j}^{k} b_{t} w_{t}\left(1-\tau_{t, i}\right) \bar{h}_{t} \frac{s_{t, j}^{k}}{\bar{R}_{t}}
$$


$\bar{R}_{t}$ is the statutory eligibility age and $R_{t}^{k}$ is the actual retirement age of household type $k$ and the cohort retiring in $t$. $N_{t, j}^{k}$ represents the number of people aged $j$, at time $t$ and in skill group $k$.

Further definitions are given by

$$
s_{t, j}^{k}=\sum_{m=0}^{j} \frac{\varepsilon_{m}^{k} h_{t-j+m, j}^{k}}{\bar{h}_{t-j+m, j}^{k}}
$$

where

$$
\bar{h}_{t}=\frac{\sum_{k=1}^{K} \sum_{j=1}^{R_{t}^{k}} \varepsilon_{j}^{k} h_{t, j}^{k} N_{t, j}^{k}}{\sum_{k=1}^{K} \sum_{j=1}^{R_{t}^{k}} N_{t, j}^{k}} .
$$

$s_{t, j, i}^{k}$ evolves according to

$$
s_{t+1, j+1}^{k}=s_{t, j}^{k}+\frac{\varepsilon_{j}^{k} h_{t, j}^{k}}{\bar{h}_{t}}
$$

The term $s_{t, j}^{k}$ links individual labor (and therefore contributions to the pension system) to the aggregate economy $\left(\bar{h}_{t}\right)$ and resembles the accumulation of pension points over the life-cycle. Accordingly, when working the average hours of the economy in a given year $t$, the household receives one pension point. Upon retirement, the quantity of accumulated pension points decides the level of pension benefits.

$\gamma_{t, j}^{k}$ is the individual specific adjustment factor of the retirement formula (2.9). The factor equals 1 if the household retires at the statutory eligibility age. If the household decides to retire earlier, there is a deduction of $\omega_{t}$ percent (adjustment rate) of pension benefits for every year. For each year of delayed retirement, there is a premium of $\omega_{t}$ percent. However, there will always be an earliest retirement age, $R_{E}$, that households cannot undercut. An overview for $\gamma_{t, j}^{k}$ is given by:

$$
\gamma_{t, j}^{k}=1+\left(R-\bar{R}_{t}\right) \omega_{t} . \quad \text { for } \quad R \geq R_{E}
$$

Finally, we introduce the mechanism to replicate the hybrid DB/DC-PAYG system, $b_{t}$, that scales the pension benefits in equation (2.9) up or down according to developments in wages and demographics. The replacement rate evolves according to

$$
b_{t}=b_{t-1} * \frac{w_{t-1}\left(1-\tau_{t-1}\right)}{w_{t-2}\left(1-\tau_{t-2}\right)} *\left(\frac{R Q_{t-2}}{R Q_{t-1}}\right)^{\mu} .
$$


$R Q_{t}$ is the ratio of the number of retirees to the number of contributors to the pension system at time $t$. Accordingly, pension benefits are scaled down (up) when net wages decrease (increase) and when the quotient $R Q_{t}$ increases (decreases) over time, which is the case in times of population aging. As Börsch-Supan et al. (2017c) argue, the parameter $\mu$ can be set as a political compromise between current voters' preferences and the financial sustainability of the pension system. The parameter captures the intergenerational distribution of the demographic risk generated by population aging. Setting $\mu=0$ stabilizes the replacement rate of pension benefits to the older generation, while $\mu=1$ stabilizes the contribution rate of the younger generation. We assume a political compromise of $\mu=0.25$ and an initial steady state of the replacement rate of $b_{0}=60 \%$ and allow it to adjust afterwards according to equation (2.14).

\subsection{Endogenous retirement decision}

There are numerous pathways into retirement, such as disability pensions, old-age pensions for women, occupational early retirement schemes, and unemployment. However, we abstract from these pathways and concentrate on the old-age public pension, which is structured as a PAYG system. A specific feature of the model is that households decide on the age of retirement. An endogenous retirement decision is modeled and households take into account the optimization of their consumption/savings and hours worked/leisure to define their own optimal age for retirement. Most modern pension systems have a window of retirement defined by an earliest and a latest eligibility age, $R_{E} \leq R \leq R_{L}$, which bracket what is colloquially termed the "normal retirement age,” $R$. Accordingly, households have a choice to retire within a given window. Retirement age is defined as the age when the household simultaneously leaves the labor market and claims pension benefits. Accordingly, a full earnings test is in place (see e.g., Börsch-Supan, et al. (2017b)).

To penalize earlier retirement and to promote a later retirement age, the pension system incorporates actuarial adjustments before and after the statutory eligibility age to pension payments if households retire before or after the statutory eligibility age, $\bar{R}_{t}$. These actuarial adjustment factors behave as already described in equation (2.13).

Finally, pension benefits, $p_{t, j}^{k}$, are corrected to the choice of the retirement age within the retirement window. The adjustment factor, $\gamma_{t, j}^{k}$, is then multiplied by the pension formula, increasing the pension benefits in proportion (2.9).

As previously mentioned, the adjustment rate, $\omega_{t}$, creates strong incentives for when to retire (Desmet \& Jousten, 2003; Gruber \& Wise, 2005; Fisher \& Keuschnigg, 2010; Börsch-Supan, et 
al., 2017b). Occasionally, it is referred to as "actuarial adjustment rate," although the term "actuarial" only applies when $\omega_{t}$ is introduced in the pension system such that the present discounted value $P D V_{t}$ of participating in the pension system for all households is independent of their retirement age, $R$.

$$
\begin{gathered}
P D V_{t}(R)=\sum_{j=R+1}^{\infty} p_{t+j}\left(R ; \omega_{R}\right) \pi_{t+j, j}\left(\frac{1}{1+r}\right)^{j}-\sum_{j=0}^{R} \tau_{t+j} w_{t+j} \pi_{t+j, j}\left(\frac{1}{1+r}\right)^{j} \\
=\text { constant for all } R \in\left[R_{E}, R_{L}\right] .
\end{gathered}
$$

The resulting $\omega_{t}$ depends on the interest rate, $r$, and survival probabilities $\pi_{t+j, j}$ of cohort $t$ for age $j$. Pension systems with benefits independent of the individual retirement age (i.e. $\omega_{t}=0$ ) are not actuarially neutral since they redistribute income from late retirees to early retirees who receive the same benefits over a longer period of time. Therefore, $\omega_{t}=0$ creates a strong incentive for workers to retire early. The same argument applies when adjustment rates are lower than the actuarially neutral value. This is the case in many countries; see Table 2.1.

Table 2.1 - Actuarial adjustment rates at earliest age of retirement benefits

\begin{tabular}{lcc}
\hline \hline & Current legislation & Actuarially neutral \\
\hline Austria & 4.2 & 7.5 \\
Canada & 7.2 & 7.3 \\
Finland & 4.8 & 7.7 \\
Germany & 3.6 & 6.3 \\
Italy & $1-2$ & 7.6 \\
Japan & 8.4 & 6.6 \\
Spain & $6.5-8$ & 7.4 \\
Sweden & $4.1-4.7$ & 6.9 \\
US & $5.0-6.67$ & 8.2 \\
\hline
\end{tabular}

The table shows the adjustment rates for statutory early retirement. Many countries have additional pathways not included here. The underlying interest rate is $2 \%$. Source: Blundell et al. (2017), OECD (2015) and Queisser \& Whitehouse (2006).

Similar actuarially neutral adjustment rates ranging between 5 and 7\% for Germany have been found by Börsch-Supan (2004), Werding (2007) and Gasche (2012) for an interest rate of 3\%, with several assumptions about future mortality.

\subsection{Production}

The production sector consists of a representative firm. Production is given by a Cobb-Douglas production function using capital stock, $K_{t}$, and aggregate effective labor, $L_{t}$, as inputs. 


$$
Y_{t}=K_{t}^{\alpha}\left(A_{t} L_{t}\right)^{1-\alpha}
$$

$A_{t}$ is technology (growing at rate $g_{t}$ ). $\alpha$ is the capital share in the economy. Since factors earn their marginal product, the wage and interest rate are given by

$$
\begin{gathered}
w_{t}=A_{t}(1-\alpha) k_{t}^{\alpha}, \\
r_{t}=\alpha k_{t}^{\alpha-1}-\delta,
\end{gathered}
$$

where $k_{t}$ denotes the capital stock per efficient unit of labor $\left(K_{t} /\left(A_{t} L_{t}\right)\right)$ and $\delta$ is the depreciation rate of capital. We also introduce a wedge between the interest rate perceived by households and the market interest rate/marginal product of capital.

\section{Methodological approach}

\subsection{Computational algorithm}

This computable general equilibrium (CGE) model has to be solved numerically. The algorithm searches for equilibrium paths of consumption, hours worked, capital to output ratios and, in case there are social security systems, pension contribution rates. We determine the equilibrium path of the OLG model by using the modified Gauss-Seidel iteration as described in Ludwig (2007). The solution of the life-cycle optimization is solved recursively by taking initial guesses for consumption at last age. Then, the model is solved backwards using recursive methods by applying first order conditions and appropriately handling the constraints. This procedure delivers first guesses for the vectors of consumption and hours worked. Labor time costs are taken into account when calculating hours worked. Costs tend to increase in age and reflect the additional burden of older workers remaining in the labor market. We then calculate savings and assets, using the budget constraint (4). The consumption profile, including consumption at last age, is then updated. This procedure is repeated until consumption and the hours profile converge. We do not allow the household to re-enter the labor market.

The endogenous decision of retirement is a second step of the algorithm and a by-product of the main optimization method. To solve it and calculate the retirement age, we use an outer loop that searches for the retirement age which maximizes the household's utility. Hereby, we carefully take into account the adjustment rate that gives incentives for early or late retirement. 
After the convergence of these inner loops, all cohorts' asset holdings and hours worked at a given year, $t$, are aggregated to receive the capital stock, $K_{t}$, and labor supply, $L_{t}$. By using equations (2.17) and (2.18), the wage and interest rate can be updated.

Our timeline has four periods: a phase-in period, a calibration period, a projection period, and a phase-out period. First, we start calculations with the assumption of an "artificial” initial steady state in 1850. The time period around 2015 is then used as the calibration period to determine the structural parameters of the model. Our projections run from 2015 until 2075. For technical reasons, the model then runs further during a transition to a steady-state population in 2150 and an additional 100-year period until the model reaches its final steady state in 2250.

\subsection{Calibration}

\subsubsection{Skill groups}

We introduce three skill groups and model them by including different life-cycle profiles for wage profiles and survival rates. In the majority of the literature, wage profiles are used to model endogenous retirement decisions (see Altig et al. (2001); French (2005); Huggett et al. (2011)). Often, these wage profiles are hump-shaped, i.e. individual productivity first increases when young and reaches a peak in middle age. Afterwards, productivity decreases again as a consequence of the aging process, like deteriorating health or declining cognitive skills. Lower wages in old age induce retirement at some point because the disutility of work outweighs the utility from receiving income. As Casanova (2013) argues, these hump-shaped wage-age profiles in econometric studies usually stem from "pooling observations of full- and part-time workers.” According to her study, however, when only full-time workers are considered, wage-age profiles are flat in later ages. This point is also discussed in detail by French (2005). When estimating hourly wage profiles, he also finds a hump-shaped pattern over age. However, as soon as he controls for part-time work and considers exclusively full-time workers in his regressions, he finds flat wage-age profiles for later ages. The latter finding is consistent with studies that show that there is no decreasing labor productivity at later ages of workers (Börsch-Supan \& Weiss, 2016). Accordingly, we introduce wage profiles that do not decline in old age, but rather stay constant after reaching their maximum (see Figure 3.1). 
Figure 3.1 - Wage profiles

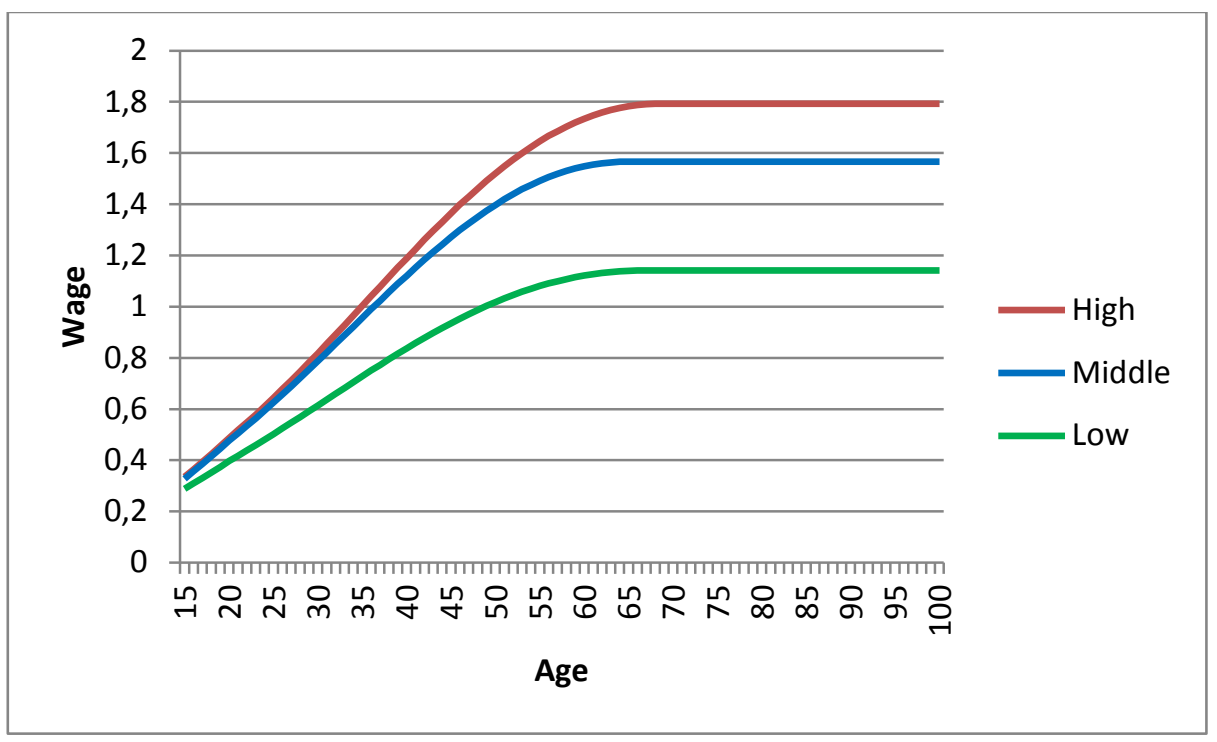

Source: own calculations.

The life-cycle wage profiles $\varepsilon_{j}^{k}$ depicted in Figure 3.1 are estimated following the procedure of Altig et al. (2001) and Fullerton and Rogers (1993). For empirical estimation, we use waves from 1984 until 2013 of the German Socio-Economic-Panel (GSOEP). The wage profiles are calculated according to the following formula:

$$
\varepsilon_{j}^{k}=e^{\zeta_{0}^{k}+\left(g+\zeta_{1}^{k}\right) j+\zeta_{2}^{k} j^{2}+\zeta_{3}^{k} j^{3}}
$$

where $j$ stands for age, $k$ for the skill group and $g$ is the constant rate of technological progress. The $\zeta$ coefficients are received according to the following procedure (see p. 581 in Altig et al. (2001)). Firstly, hourly wages are regressed on fixed-effect dummies, age-squared, and interactions between age and other demographic variables. Secondly, the coefficients obtained from the previous regression are used to generate predicted life-cycle wage profiles. As a next step, the data is sorted according to the present value of lifetime income and three skill groups are generated by quintiles. Lastly, the coefficients of equation (3.1) are estimated from the simulated data profiles of each of the three skill groups. These estimated profiles $\varepsilon_{j}^{k}$ are used in equation (2.5) to determine individual life-cycle wage profiles for the three skill groups, taking the prevailing aggregate wage rate $w_{t}$ in the economy as given.

As a second dimension of heterogeneity, we include mortality risk, which increases with age. Type-dependent survival rates, $\pi_{t, j}^{k}$, for the three skill groups are computed in several steps. Danish register data (Kallestrup-Lamb \& Rosenskjold, 2017) suggests that there is a gap in life expectancy of two years between the middle and highest income/wealth groups, while there is a larger gap of 4-4.5 years between the low and middle groups. As a second step, average survival 
rates for the EU28 countries (Eurostat, 2010) are adjusted such that they reproduce the aforementioned gaps in life expectancy. These estimates of the unconditional survival rates, $\pi_{t, j}^{k}$, for the three skill groups are shown in Figure 3.2. They are used in equation (2.4) to discount future utility in addition to pure time discounting, $\beta^{j}$.

Figure 3.2 - Unconditional survival rates

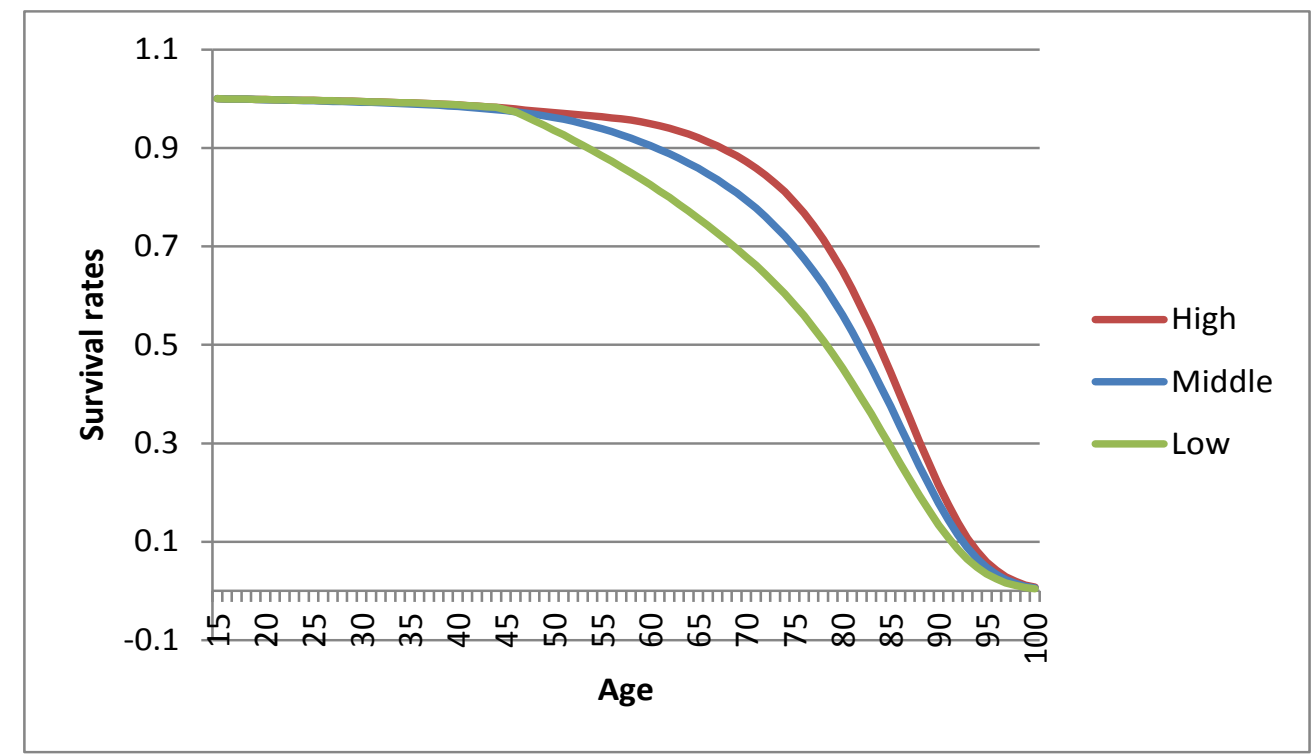

Source: own calculations.

\subsubsection{Consumption preferences and time costs of working}

Representing a parameter that changes through the life-cycle, Figure 3.3 shows the life-cycle profile of the consumption weight parameter. In general, we assume declining preferences of consumption for mimicking the aging process, like degenerating health or cognitive decline. We then model the consumption weight parameter as age-dependent. These high preferences toward leisure during old age (low preferences on consumption) are a way to induce retirement. The decline is assumed to be 0.05 . Accordingly, with initial preferences of 0.62 , we assume that preferences could decrease until reaching 0.57 at the end of life. 
Figure 3.3 - Consumption preference profile

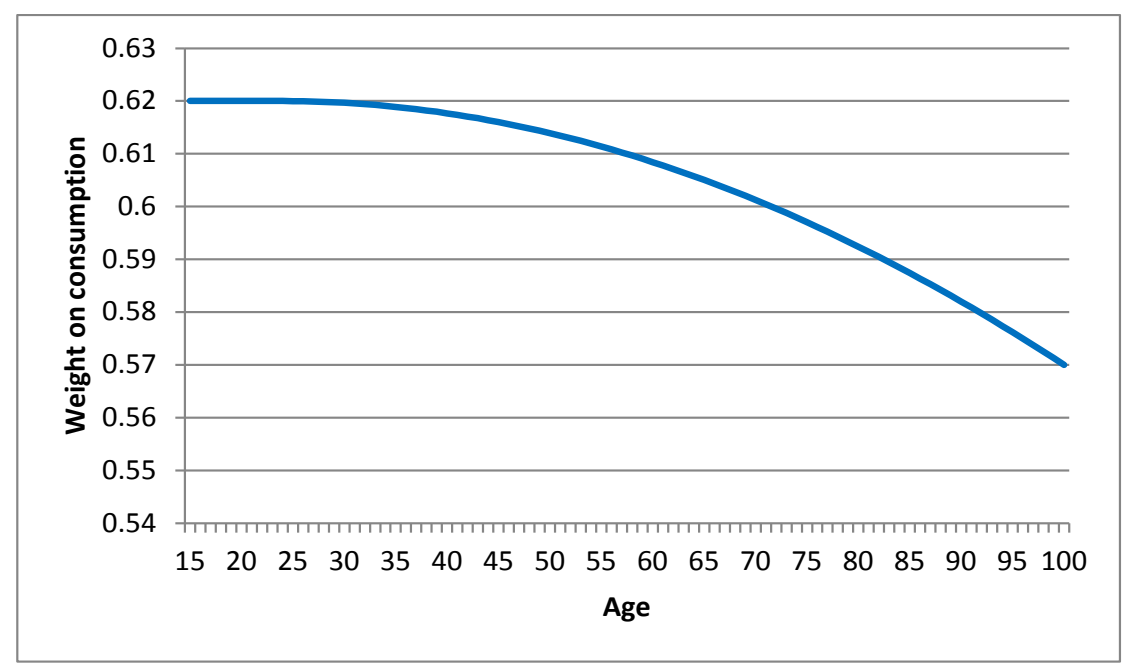

Source: own calculations.

Following French (2005), Rogerson and Wallenius (2013) and Cogan (1981), we model time costs $\vartheta\left(h_{t, j}^{k}\right)$ as time costs that are deducted from leisure and emerge when hours worked are positive. If the household decides not to work, there are no time costs. Intuitively, they reflect costs like commuting time to work, but also other costs associated with declining health, opportunity costs, or subjective value given to work by workers. Therefore, we assume that time costs increase with age and are equal for all groups of individuals. These costs are modeled considering two components. As it is shown in equation (2.3), there is $\chi_{\mathrm{j}}$, which is age-dependent, and the ratio $\frac{\chi_{j}}{\left(1+h_{t, j}\right)^{\xi}}$. We assume that $\chi_{j}$ increases over time until a maximum value of $29 \%$ of total time available for the household. This value is attained only at age 80. At the highest possible retirement age, costs can reach a maximum of 29\% (see Figure 3.4).

Figure 3.4 - Time costs of working

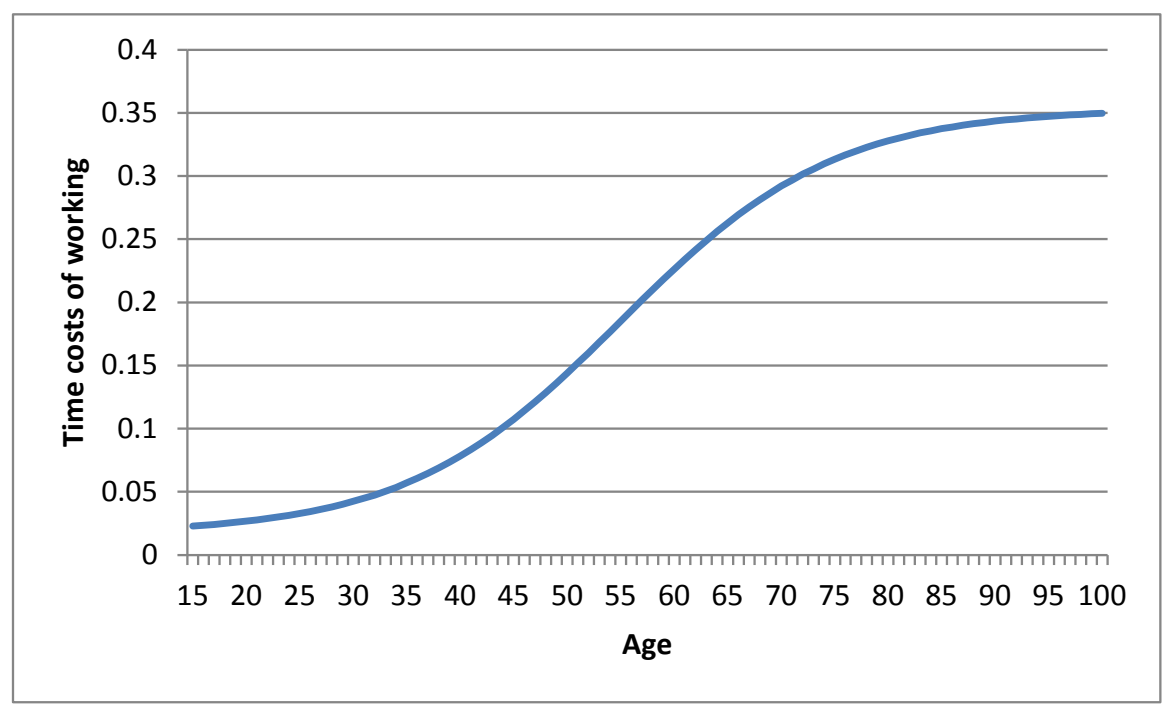

Source: own calculations. 
However, since they also depend on hours, costs never reach such high values. Due to the ratio in the cost function, the calibrated value of $\xi=12$ and the decisions of households regarding leisure and consumption, the cost function will never attain the maximum cost value at any age but will asymptotically approach it for higher working hours. Note that with a value of $\xi=12$, the cost function quickly approaches zero when hours worked are small. We use this shape of the cost function to avoid discrete jumps in time costs at $h_{t, j}=0$. Instead, the function smooths the cost function for values of hours worked close to zero. These assumptions lead to a more realistic hours profile and, of course, also shape retirement decisions of households.

\subsubsection{Structural parameters and population data}

The life span of the household is assumed to be 100 years. The household enters the labor market at age 15. The structural parameters of the household model are chosen to achieve several calibration targets with reference to other studies. Table (3.1) gives an overview:

Table 3.1 - Parameter calibration

\begin{tabular}{lc}
\hline \hline \multicolumn{1}{c}{ Parameter } & Values \\
\hline Discount rate $(\rho)$ & 0.02 \\
Risk preference $(\theta)$ & 2 \\
Earliest retirement age & 60 \\
Latest retirement age & 72 \\
Initial steady state replacement rate & 0.6 \\
Adjustment rate & 0.036 \\
Capital share in production $(\alpha)$ & 0.33 \\
Growth rate of labor productivity $(g)$ & 0.015 \\
Depreciation rate of capital $(\delta)$ & 0.05 \\
Demographic risk sharing $(\mu)$ & 0.25 \\
Wedge (capital income tax) & 0.264 \\
\hline
\end{tabular}

We choose parameter values such that the simulated moments of our model match their empirical counterparts in the data. Our calibration year is 2017. We target a capital-output ratio of 2.6 (based on estimates of the stock of fixed assets to output). In addition, parameter values are chosen such that people retire around the age of 62 to 64 in the year 2017, which is close to the actual retirement ages in several European countries in previous years (Börsch-Supan, et al., 2017a; OECD, 2015). To achieve these targets, the discount rate, $\rho$, is set to 0.02 (see overview by Frederick et al. (2002)). The risk preference parameter, $\theta$, is assumed to be 2 , which makes the household slightly risk averse and lies in the middle of estimates in the literature (see overview by Bansal and Yaron (2004) and Browning et al. (1999)). The capital share, $\alpha$, in the economy is assumed to be 0.33 and annual productivity growth is $1.5 \%$. The depreciation rate of capital is $5 \%$ per year. For the different macroeconomic regimes, the simulation method to implement lower 
interest rates considers a wedge between marginal productivity of capital and the interest rate perceived by the households is assumed to be $26.4 \%$. For the low growth regime, we assume productivity growth to be $0.5 \%$. This will force economic growth to be in the extreme regime we want to test.

We choose a retirement window from $R_{E}=60$ until $R_{L}=72$. Age 60 was the former earliest legal retirement age for women in several countries, for instance in France (age 61), Italy (age 62) or Germany (age 63) (Social Security Administration, 2014; Deutsche Rentenversicherung Bund, 2015a; OECD, 2015) and it is therefore taken as the first possible retirement age. Theoretically, there is no upper bound for late retirement in existence. However, to keep some plausibility in the decisions, we assume 72 as the highest possible retirement age, in accordance with US Social Security regulations. In fact, in 2014 only 1.6\% of all new pensioners in Germany retired at or after the age of 66 (Deutsche Rentenversicherung Bund, 2015b). Therefore, taking age 72 as an upper bound for retirement is a reasonable and sound assumption. We assume the lower bound value of current adjustment rates across OECD countries (see Table 2.1), therefore $\omega=3.6 \%$ (see equation (2.13)). As described in Section 2.3, the replacement rate adjusts endogenously and scales the pension system up or down depending on demographic evolutions and economic circumstances. We hold the replacement rate constant at a value of 60\% until the year 2004 and let it adjust from that year onward according to equation (2.14).

Demography is described by the size of each cohort, the survival of that cohort and additions through net migration. We treat all three demographic forces as exogenous. The size of the population aged $j$ in period $t$ is given recursively by

$$
N_{t+1, j+1}=N_{t, j} \varphi_{t, j}
$$

where $\varphi_{t, j}$ denotes the age-specific conditional survival rate. The original cohort size for cohort $c$ depends on the fertility of women aged $k$ at time $c=t-j$ :

$$
N_{c, 0}=\sum_{k=0}^{\infty} f_{c, k} N_{c, k}
$$

Population aging has three demographic components: past and future increases in longevity, expressed by $\varphi_{t, j}$; the historical transition from baby-boom to baby-bust expressed by past changes of $f_{c, k}$; and fertility below replacement in many countries expressed by current and future low levels of $f_{c, k}$. Population data for Germany, age distributions, and assumptions on projections for fertility, mortality, and migration rates are taken from the Human Mortality Database (2016). Life expectancies are also computed from life tables provided by this source. 


\section{Comparisons between pension reforms}

As referred to before, we start by analyzing the effects of different types of pension reforms. This delivers a clear message on how each reform impacts retirement ages, the sustainability of the pension system, represented here by replacement rates, and contribution rates behavior. Furthermore, we examine how different skill groups' welfare is affected by each reform and how unequal the welfare gap between those groups becomes. This last step is undertaken through the analysis of consumption equivalent variation (CEV) for each group through time. We will start with the baseline scenario that is also the benchmark regime scenario, which will be the basis of comparison in Section 5 for the other two macroeconomic regimes. Afterwards, each reform will be separately analyzed and a summary of all reforms and their own specific effects will be made at the end of this section.

\subsection{Baseline scenario}

As a first step, we describe a scenario without any reform that will serve as the baseline case. The parameters used are described in the previous section. This baseline scenario is calibrated such that outcomes match our calibration targets described above. First, the capital-output ratio is 2.65. Second, households devote $70 \%$ of their available time (not counting sleep) to work. Third, households retire around age 62 in the year 2017. All later reform scenarios will be compared to this baseline case.

Figure 4.1 depicts the evolution of the resulting retirement ages over time for the three skill groups. Note that the horizontal axis shows the point in time when a specific cohort is entering the labor market at age 15 (cohorts' entrance year). For instance, the first data point for the lowest skill group means that the cohort entering the labor market in 1965 (born in 1950) retires at age 61, i.e. in the year 2011. 
Figure 4.1 Retirement ages - Baseline scenario

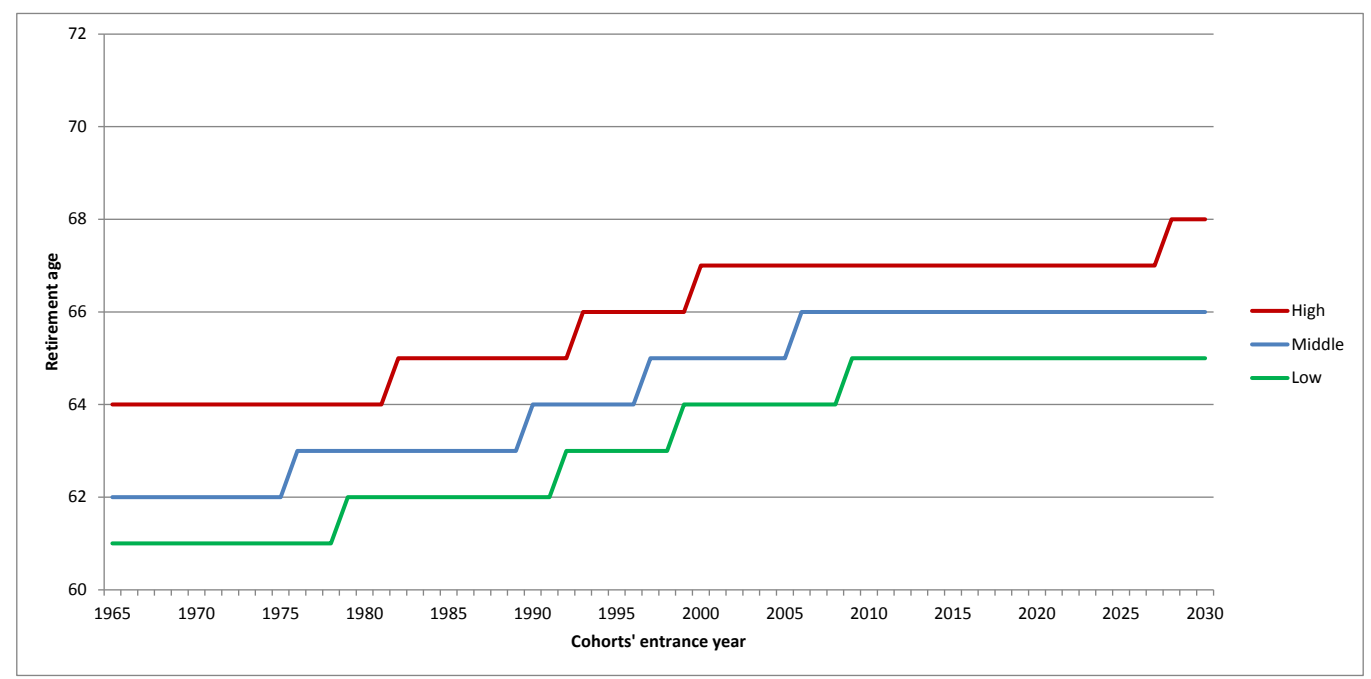

Source: Own Calculations.

Three main findings can be derived immediately. The first result suggests that agents generally choose early retirement. During the given retirement window of 60-72 during which retirement is allowed to take place, agents retire between the ages of 60 and 65 for cohorts entering the labor market before 1975. This mimics several public pension systems that currently produce incentives for early retirement (for further simulations concerning this topic, see Gasche (2012)). This is mainly due to too low adjustment rates. As described in Section 3.2, we use an average value corresponding to many developed aging countries: for every year of retirement before the statutory eligibility age, pension payments are reduced by $3.6 \%$.

Second, retirement ages are low for early years and increase gradually over time for all three skill groups. The reasons for this general evolution are twofold. One is that increasing statutory eligibility ages creates incentives for later retirement because households would be penalized more by higher accumulated deductions. Secondly, interest rates decrease over time: due to population aging, labor becomes scarcer and the capital stock rises because of higher savings. This increases the relative wages vis-à-vis the decreasing interest rate, which induces incentives to work longer. As an overall effect, all groups' retirement ages rise even without any exogenous reform.

As a third finding, households from low skill groups retire earlier than those from the high skill group. This stems from two main causes. On the one hand, higher consumption preferences of high skill groups lead to later retirement, as individuals prefer not to be penalized in present and future consumption by the deductions imposed by the adjustment rates. Moreover, they value consumption more than leisure, meaning they prefer to continue to work additional years and 
benefit from higher income and, hence, higher consumption. On the other hand, the structure of the pension system influences their decisions. Benefits paid out to pensioners strongly depend on average wages in the economy. For high skill households, this means a substantial drop in income (low replacement rates), whereas low skill groups are not affected so severely (high replacement rates). The opportunity costs of retirement are therefore higher for high skill agents and thus lead to later retirement.

Following demographic trends, the equilibrium path of contribution rates to the PAYG pension system and the replacement rate are depicted in Figure 4.2. Note that the horizontal axis refers to actual years and not to the cohorts' entrance years. The contribution rates are calculated by assuming that the pension system's budget constraint has to be balanced every year (equation 2.8). The replacement rate (equation 2.14) is defined by the evolution of demographics and wage growth.

Figure 4.2 Contribution Rates and Gross Replacement Rates

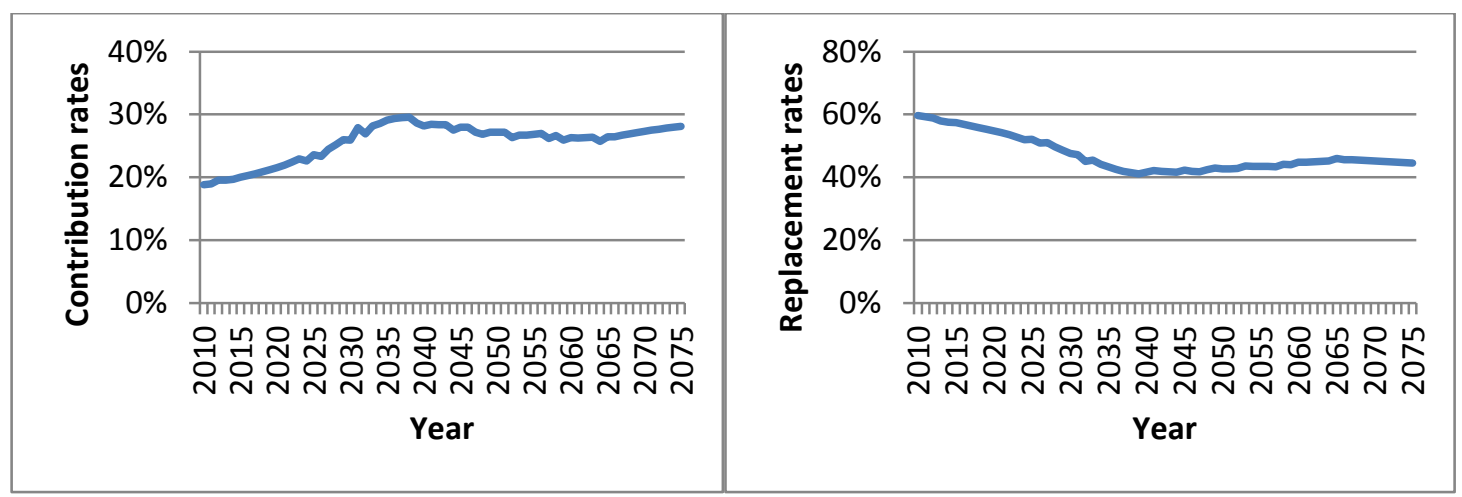

Source: Own Calculations.

Not surprisingly, the contribution rate rises from levels around $18 \%$ to levels around $28 \%$. The initial increase is very steep due to the retirement of the Baby Boomers. However, rates would rise even more if it was not for the replacement rate (see Figure 4.2, right), which dampens some of the demographic pressure on the PAYG pension system: the factor decreases simultaneously from values around $60 \%$ to slightly below $50 \%$ and stabilizes there.

\subsection{Increasing the statutory retirement age}

In order to create incentives for older ages to work longer and to make public pension systems more sustainable, many countries have increased (or are still increasing) their statutory eligibility age at which people can retire without any deductions. In France, the statutory eligibility age is gradually rising from age 65 to 67 from 2016 to 2022 and in Italy it will reach 67 in 2028. Similarly to the evolution in these countries, the statutory eligibility age is also gradually rising from age 65 to 67 in Germany from 2012 until 2029. In detail, the statutory eligibility age increases one month every year until 2023 and two months every year from 2024 onwards. As an 
assumption we use the pathway of Germany in our model. In this section, we implement this reform in our simulations. Figure 4.3 depicts the evolution of the resulting retirement ages over time for the three skill groups.

Figure 4.3 - Retirement ages

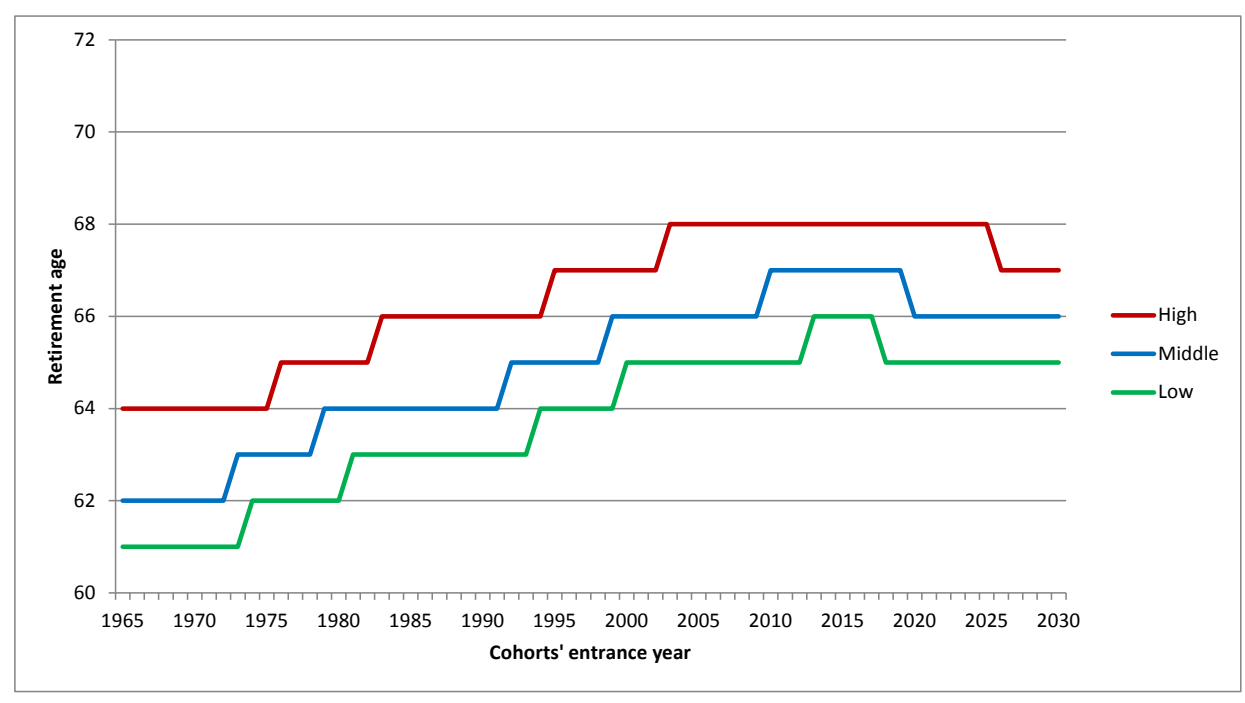

Source: own calculations.

Again, the same three general findings as in the baseline scenario still hold: generally low retirement ages (60-66) for early cohorts, increasing retirement ages over time and higher retirement age for higher skill groups. However, the increase of the statutory retirement age by two years indeed influences the actual retirement ages for several cohorts. To see this more precisely, Figure 4.4 shows the difference in retirement ages between the reform and the baseline scenario for every income group. Positive values mean that households retire later in the reform scenario than in the baseline case for a specific cohort. Zero values mean that cohorts retire at the same age in both scenarios. 
Figure 4.4 - Retirement ages (differences)

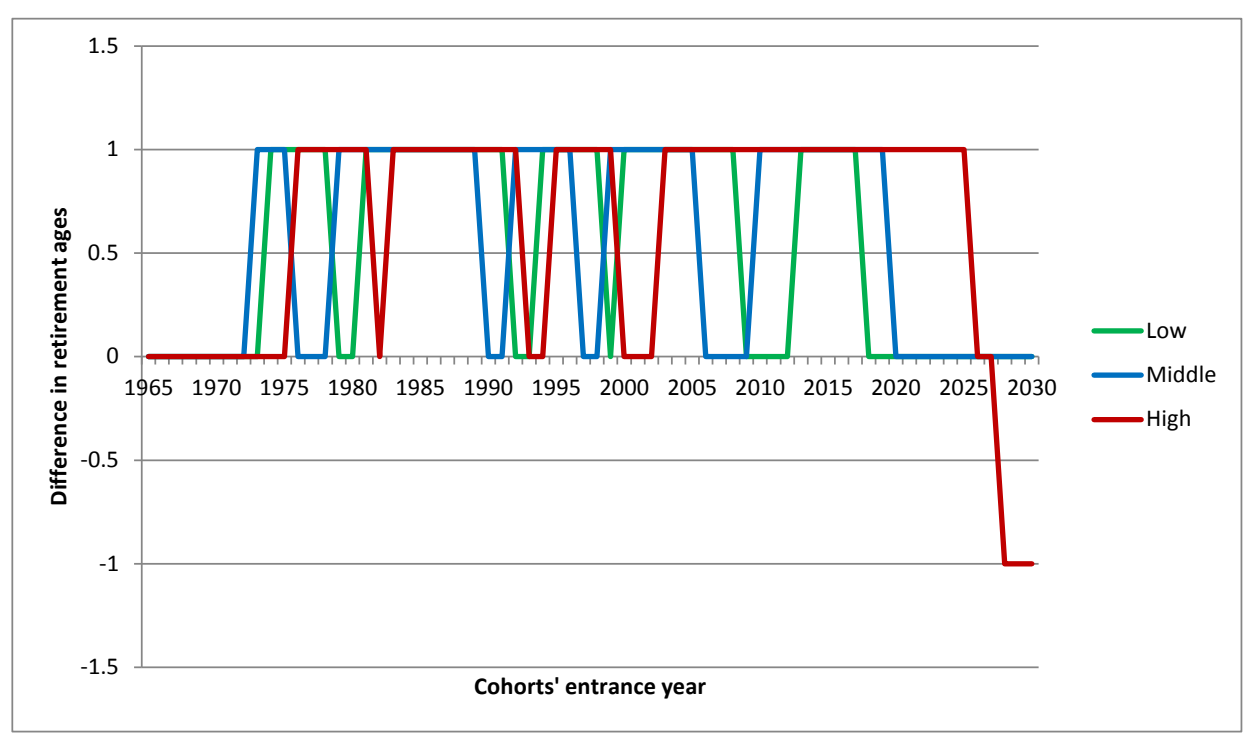

Source: own calculations.

We can observe the following outcomes. First, cohorts entering the labor market before 1972 do not change their retirement ages (zero values in Figure 4.4): since these cohorts retire before or only shortly after the reform is implemented, they do not change their retirement behavior. Second, for cohorts entering the labor market after 1972, there is an increase in retirement ages. The reason is the change in retirement incentives: if the statutory retirement age is elevated by two years from 65 to 67, sticking to the hypothetical pre-reform retirement age would cost two more years of deductions from pension benefits. Since households want to avoid this additional penalty, they increase their actual retirement age. However, it is essential to note that this increase is smaller than the change in the statutory retirement age by two years: most of the time, there is only an increase of one year in retirement ages. This finding is in line with previous studies (Fehr, et al., 2012). Some cohorts or income groups do not even change their retirement behavior at all (e.g. the middle skill group for cohorts entering after 2020). This group already retires relatively late in the baseline scenario and therefore does not adjust its retirement ages upwards.

This observation can be interpreted as another form of backlash in pension reform: instead of working two years longer and reacting to the reform one to one, households also optimize hours worked during their working life and only retire roughly one year later. This reaction is important to understand when thinking about pension reforms or reform proposals and their impact on the pension system.

The ultimate goal of pension reforms, such as increasing the statutory retirement age, is to make public pension systems more sustainable. One indicator for sustainability is the contribution rate, i.e., the percentage of gross work income that workers have to contribute to the PAYG public 
pension system. Figure 4.5 (left) displays the evolution of these contribution rates after the reform in 2012.

Figure 4.5 - Contribution rates and replacement rates

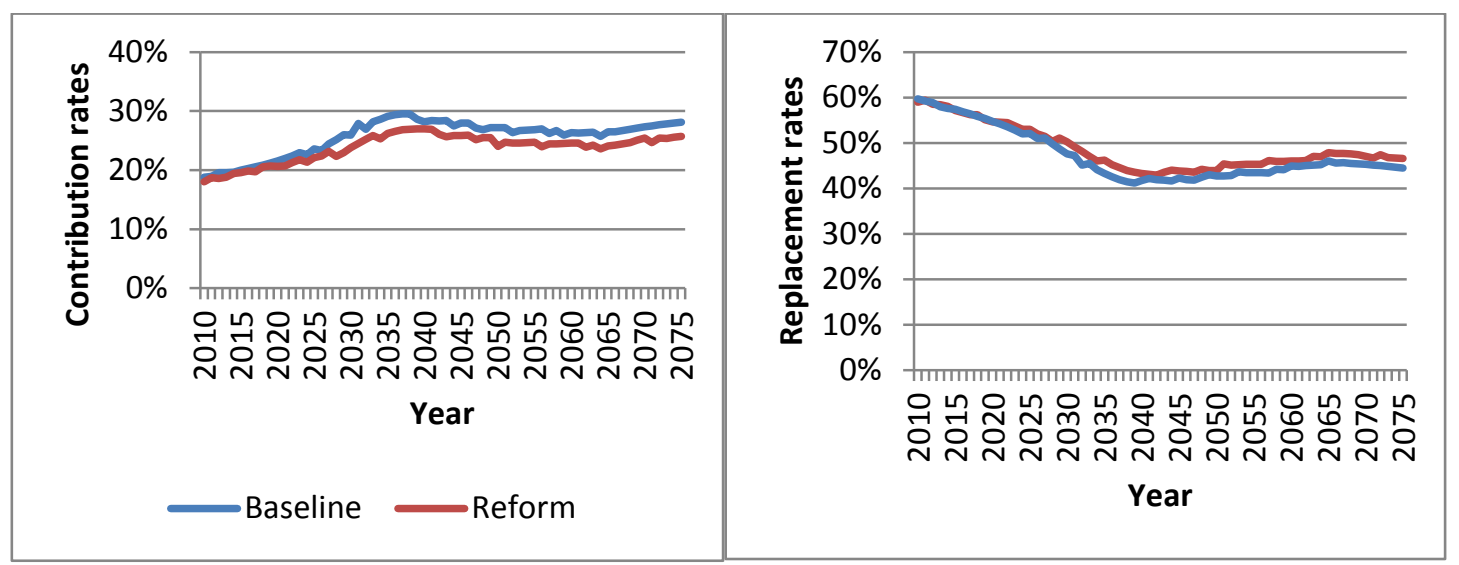

Source: own calculations.

It becomes clear that the reform meets its goal: the contribution rate is roughly 2 percentage points lower if there is an increase in the statutory retirement age. At the same time, not only is the contribution rate lower than in the baseline case but also the average replacement rate in the economy is higher (see Figure 4.5, right). It is roughly 2-3 percentage points higher in the reform case than in the baseline scenario.

A lower contribution rate combined with a higher replacement rate is a clear argument that the reform indeed makes the pension system more sustainable despite endogenous reactions of households to the reform (reform backlashes in retirement ages).

In addition to a more sustainable public pension system after the reform, lifetime utility of households is also higher in the reform case. Figure 4.6 shows the consumption equivalent variation for cohorts entering the labor market at the time indexed on the horizontal axis. The vertical axis shows the percentage of lifetime consumption that a household would be given in the baseline scenario in order to be as well off as in the reform scenario. Positive values, therefore, denote that cohorts in the reform case are better off than in the baseline scenario. 
Figure 4.6 - Consumption equivalent variation

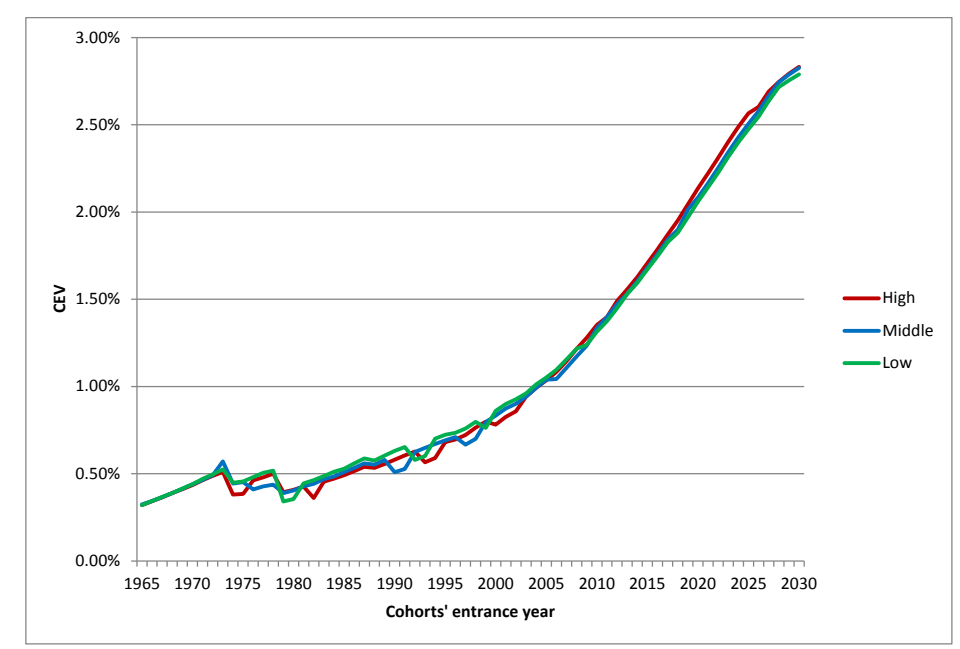

Source: own calculations.

Households entering the labor market in the second half of the $20^{\text {th }}$ century are only slightly better off since they only profit during retirement from the increasing replacement rates or late in working life from lower contribution rates. For cohorts that enter after the reform is implemented, they see their welfare increasing substantially: CEVs increase almost $3 \%$ and stay at this level afterwards. In sum, small short-term welfare consequences are followed by large long-term welfare gains. We can also observe that this reform does not grant sufficient additional gains in work income for the low skilled households, which could lead to a more than proportional increase in consumption and welfare in comparison to the high skilled. Therefore, welfare effects are similar for all income groups, which means inequality between skill groups remains unaffected.

\subsection{The 2:1 reform}

Aging, as the main driving force of imbalances on pension systems around the world, is caused by increasing life expectancy. As we presented before, several reforms can have a positive effect on halting the pernicious outcomes on the pension system. However, reform success turns out to be only temporary until the previous imbalances, which were controlled a decade before, emerge again since life expectancy is persistently increasing. This is why an increase in the statutory eligibility age today to 67 would lead, in about a decade, to the same current problems faced by the pension system. It would again require a discussion about whether or not to increase the retirement age, to which age, and when.

A possible solution for this, which was previously presented by Börsch-Supan (2007), offers a systematic and clear rule that could be understood by any citizen and that accommodates changes on demographic dynamics. This rule, called the 2:1 rule, dictates that sufficient increases in life 
expectancy of individuals should be compensated by increases in the statutory eligibility age on a proportional basis. As a rule of thumb, since an individual works approximately two thirds of his life, for instance, an increase of 3 years in life expectancy should promote an increase of 2 years in the statutory eligibility age and 1 year spent in retirement - the 2:1 rule. In order to implement this rule, we define a benchmark life expectancy age of cohorts retiring in 2017. From this year on, any cohort whose life expectancy exceeds 1.5 years from the benchmark will face an increase in the statutory eligibility age of 1 year. This life expectancy will be the new benchmark and later on, any other cohort with 1.5 years more of life expectancy will face another increase in the statutory eligibility age.

Table 4.1 - Evolution of statutory eligibility ages

\begin{tabular}{cc}
\hline \hline Years & Statutory retirement age \\
\hline $2017-2021$ & 65 \\
$2022-2028$ & 66 \\
$2029-2037$ & 67 \\
$2038-2042$ & 68 \\
$2043-2051$ & 69 \\
2052 - onwards & 70 \\
\hline
\end{tabular}

Source: own calculations using data from the Human Mortality Database (2016).

After we examined an increase of the statutory retirement age, we can already expect that the 2:1 reform will also lead to a raise in actual retirement ages. Since the forecasts of life expectancies suggest a continuous climb through time, the 2:1 rule will be automatically applicable such that statutory eligibility ages will increase during the life span under our analysis. As Figure 4.7 shows, actual retirement ages will follow this trend and they continually rise with time. 
Figure 4.7 - Retirement ages

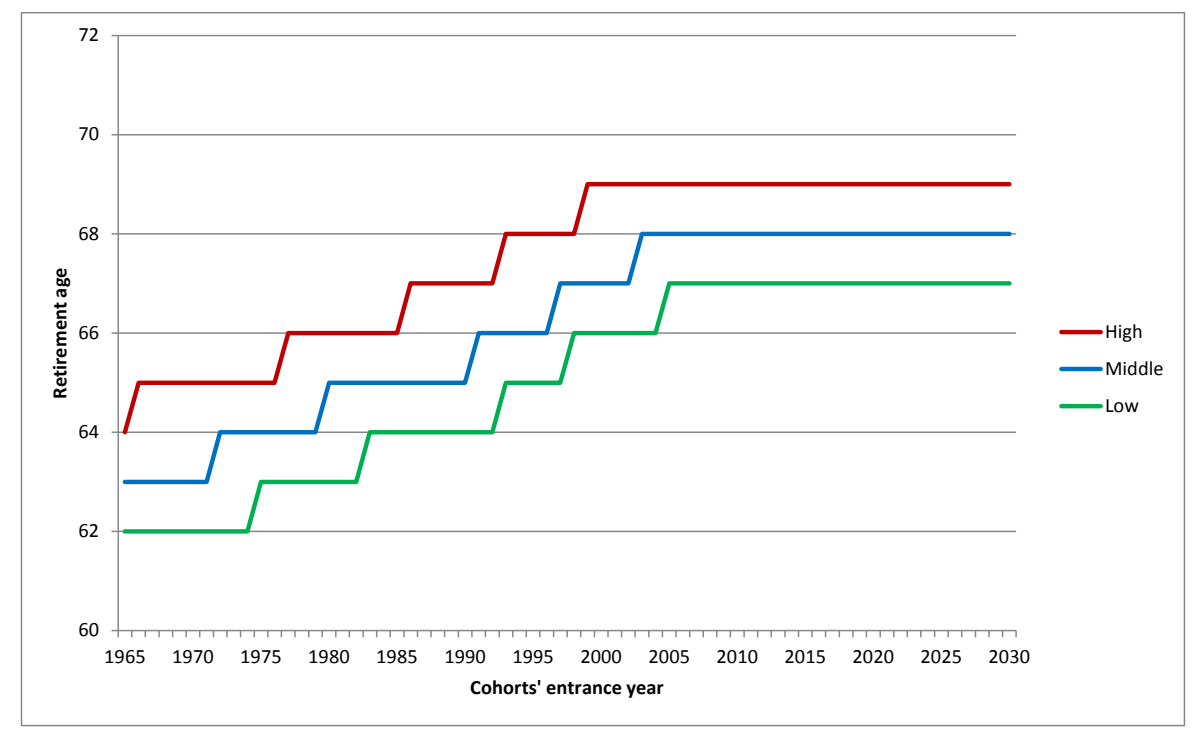

Source: own calculations.

In general, retirement ages increase due to changes in the statutory eligibility ages. Actuarial adjustment rates will also take into account the new threshold for retirement age, meaning they now assume a value of zero at the new statutory eligibility age. Therefore, negative adjustment rates will now be prevalent until later ages. This augments incentives for later retirement. If cohorts keep the same behavior as previous cohorts, they would see a larger share of their pensions being cut due to higher adjustment costs.

We see that all skill groups increase their retirement ages consistently over time. The high skill group is still the one with later retirement, but the most significant outcome is the rapid increase in retirement ages of the lowest skill groups. They perceive the high costs of retiring too early and react to it by quickly increasing their retirement ages. Only the actuarial neutral adjustment rates reform has a higher impact on retirement ages. Increases in retirement ages are substantial. All skill groups raise their actual retirement ages by 2-3 years (see Figure 4.8) for cohorts entering the labor market after 1985. 
Figure 4.8 - Retirement ages (differences)

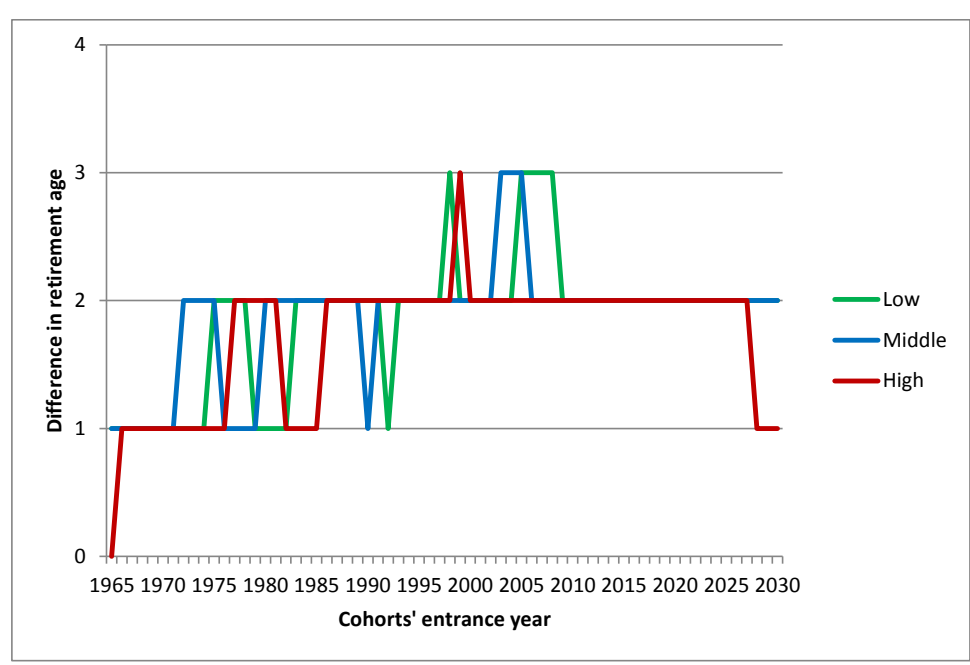

Source: own calculations.

The difference between the baseline and this scenario is slightly smaller in earlier and later years for the highest group (Figure 4.8) because retirement ages are already high in the baseline scenario, which means that differences tend to be lower in the later years of our time range. Therefore, it does not reflect a decrease in retirement ages in the reform scenario but a convergence of retirement ages close to 72 .

Figure 4.9 (left) shows the corresponding contribution rates. We observe that contribution rates attain a lower value in the long run than in the baseline scenario (3-5 percentage points (p.p.) less in the mid-term and long-term, respectively). Comparatively with other reforms examined, this scenario also exhibits the lowest long-term contribution rates. The evolution of the replacement rates is also very beneficial since it tends to be almost 5 p.p. higher than in the baseline scenario. The reason stems from the increase in the actual retirement ages, which allows for a postponement of the payment of benefits and for payments to be at a lower cost. This is due to actuarial adjustments that are linked to the new statutory eligibility ages, which is one of the advantages compared to the scenario with actuarial neutral adjustment rates. These reforms create incentives for later retirement without raising the cost of payment, which occurs when we just increase adjustment rates. Since adjustment factors higher than one are only captured when retirement occurs at very late ages, this leads to more years of work and fewer years of benefits. 
Figure 4.9 - Contribution rates and replacement rates

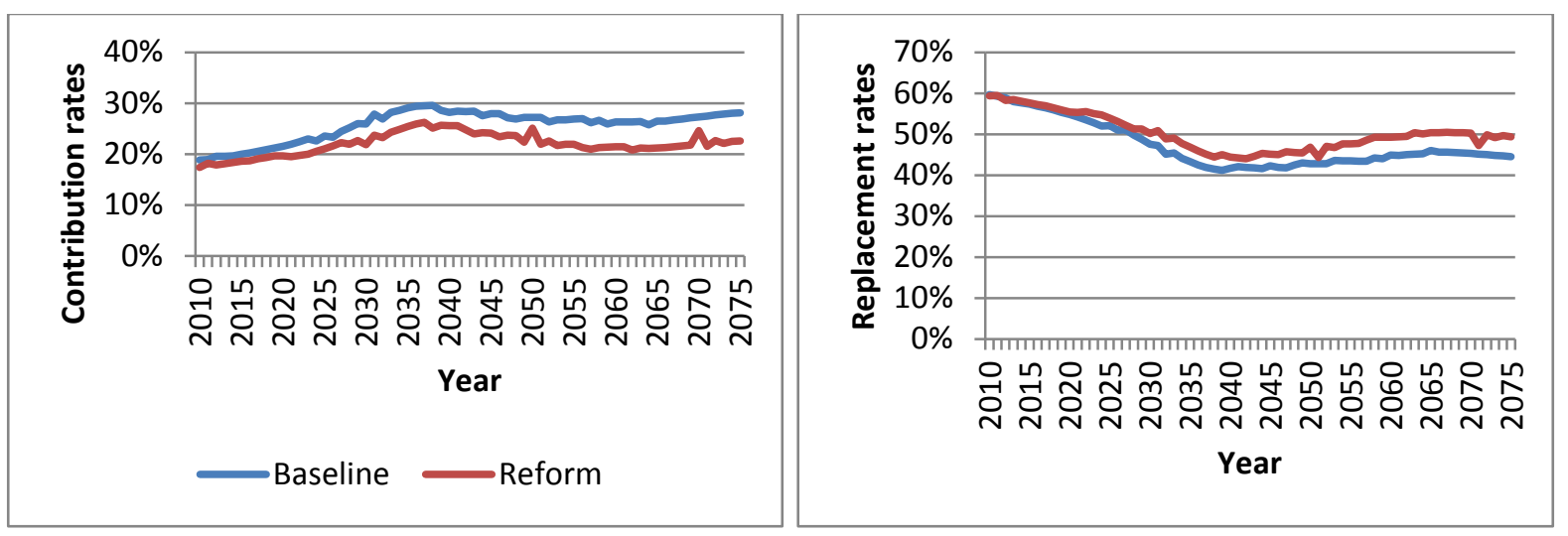

Source: own calculations.

Comparing utility in terms of the CEV, Figure 4.10 shows how different cohorts benefit from this new reform.

Figure 4.10 - Consumption equivalent variation

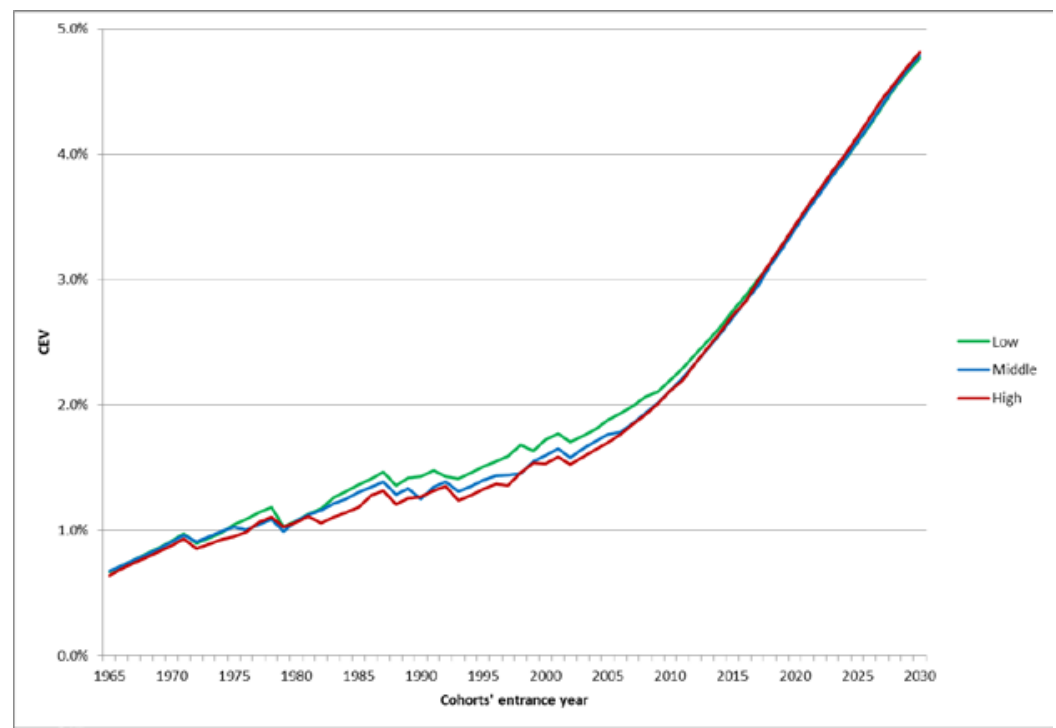

Source: own calculations.

As expected from the previous explanations, cohorts are substantially better off with this reform. The gains attained are almost 7\% for cohorts entering in the long-term. These values are higher than in any other scenario and corroborate with what we previously explained regarding lower contribution rates and higher replacement rates than in the baseline case. The lower contribution rates make cohorts extremely better off since they earn more and pay less than in the baseline scenario or in any other scenario. Older cohorts do not benefit very much because they only benefit in the last years of their lives based on the new changes in the pension system.

Regarding distributional effects, two different phases should be distinguished. For cohorts entering the labor market before 2010, low skilled groups benefit more in terms of welfare 
because this cohort mainly profits from increasing replacement rates. This happens because the 2:1 reform, in comparison to the previous reform, only fully takes place in the very long run (as visible in Table 4.1). Therefore, for older cohorts, the main effect of higher statutory retirement ages works through a higher replacement rate. Low skilled households benefit more than high skilled because the growth in their pension income represents a proportionally larger increase in income than for the high skilled, which expands their consumption possibilities. This will tighten the inequality gap between high and low skilled households.

In the long run, the decrease in contribution rates becomes more prominent. In reaction to lower contribution rates, high skilled households work longer both intensively and extensively and their reaction is stronger than that of low skilled. Therefore, welfare gains of these cohorts are similar and even larger for skilled households. In contrast to the short run, the inequality gap does not close.

\subsection{Actuarial neutral adjustment rates}

In the previous scenario, we used relatively low adjustment rates of 3.6\%, which mirrors early retirement incentives given by many pension systems across countries (see Table 2.1). However, actuarially neutral adjustment rates ranging from 5 to 8\% have been found by Börsch-Supan (2004), Werding (2007), Gasche (2012) and Queisser and Whitehouse (2006) for the different OECD countries. Therefore, in this section we simulate our model with adjustment rates closer to the actuarial neutral values and use the lower bound early adjustment rate of $6.3 \%$ for early and late retirement. We further assume that this hypothetical reform is implemented in the year 2017. From then on, adjustment rates rise linearly from their current levels until the year 2032, where they reach their final values of 6.3\%. Figure 4.11 displays the resulting retirement ages. 
Figure 4.11 - Retirement ages

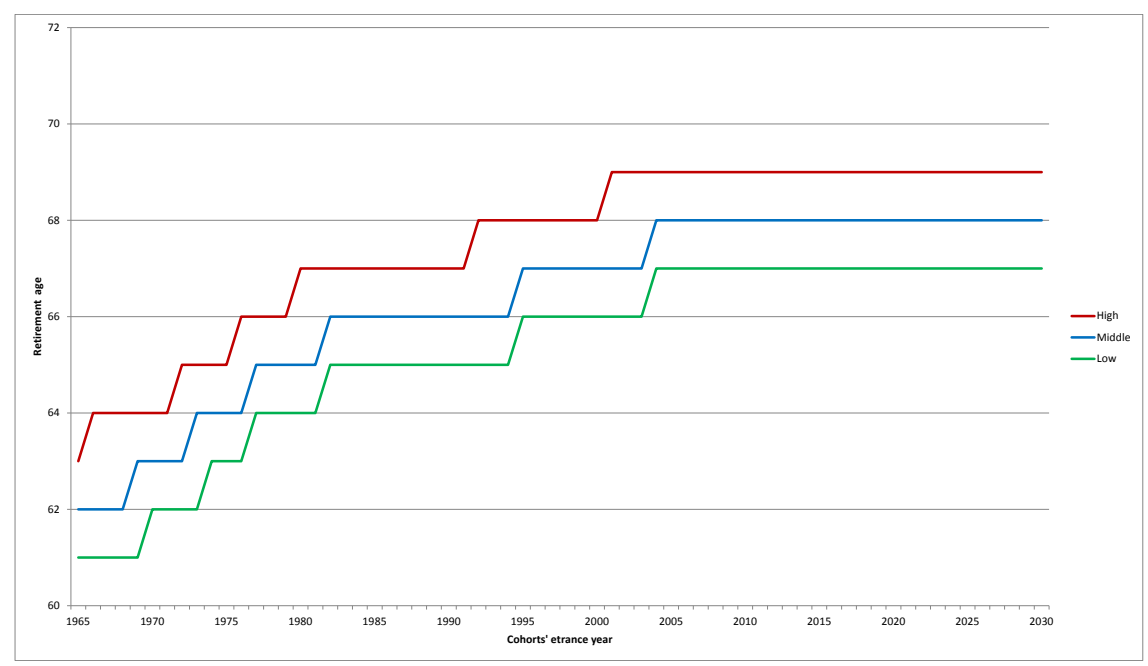

Source: own calculations.

As a consequence of higher adjustment rates, retirement ages increase faster and steeper than in the baseline scenario (see also Figure 4.12). This finding is in line with previous literature on earnings tests and actuarial adjustment rates (Börsch-Supan, et al., 2017c). Households, therefore, react strongly to the change in incentives of the pension system by adjusting their retirement behavior accordingly.

Figure 4.12 - Retirement ages (differences)

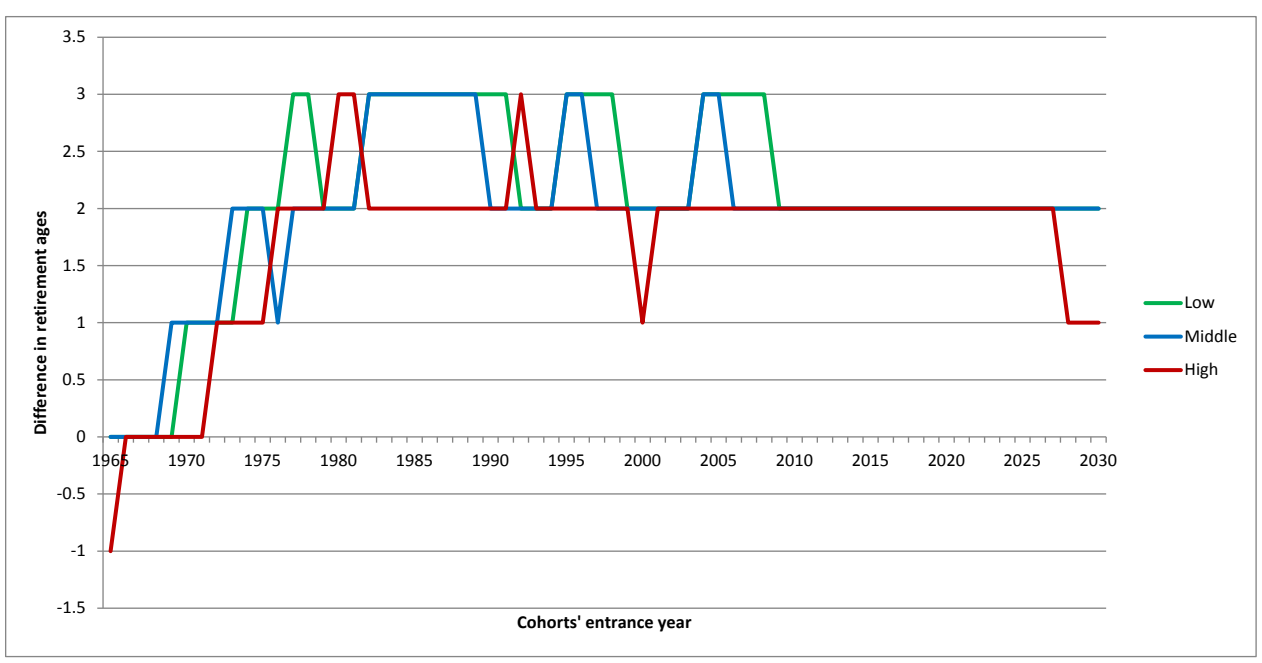

Source: own calculations.

To see this more precisely, Figure 4.12 shows the difference in retirement ages between the reform and the baseline scenario for every skill group. As Figure 4.12 reveals, households generally retire 2-3 years later in this alternative scenario. Only the highest skill group postpones retirement by less than 2 years because it already retires at high ages in the baseline scenario. 
The ultimate goal of pension reforms, such as increasing the adjustment rates, is to make public pension systems more sustainable. One indicator for sustainability is the contribution rate, i.e. the percentage of gross work income that workers have to contribute to the PAYG public pension system. Figure 4.13 (left) displays the evolution of the contribution rates in the baseline scenario and in the case with 6.3\% deductions (Reform). Higher adjustment rates clearly lower the contribution rates relative to the baseline scenario by about 2 p.p. in the mid-term. On the one hand, this can be explained by the later retirement of households, which relaxes the budget equation of the PAYG pension system since there are fewer pensioners at every point in time. On the other hand, households that might still retire early receive much lower pension benefits due to a higher penalty that decreases total pension expenditures.

In the long-term, differences in contribution rates are almost non-existent because the advantages for the system from later retirement ages are overcome by higher adjustment rates, which increase payments to retirees and the burden on the system.

Figure 4.13 - Contribution rates and replacement rates

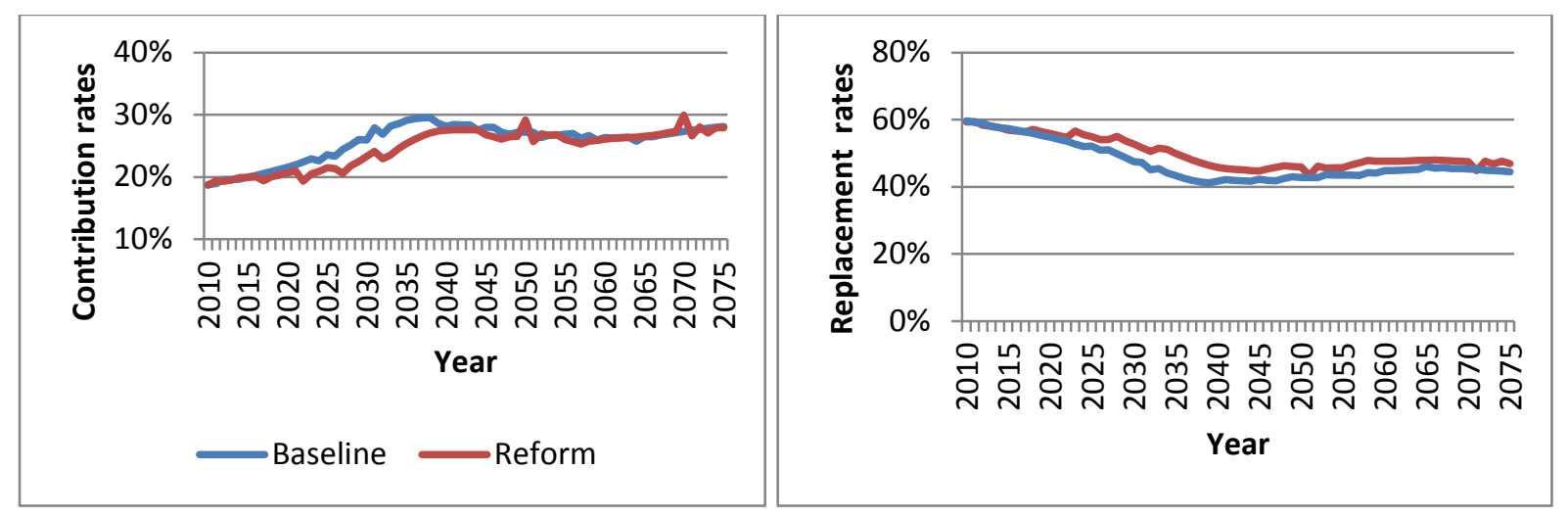

Source: own calculations.

The same argument holds for the replacement rate (see Figure 4.13, right). Also here, the reform leads to a slightly higher replacement rate. Note that individual pensions are substantially higher than in the baseline scenario since households gathered more pension points by working longer (compare individual pension equation 2.9). Figure 4.13, however, depicts the evolution of the aggregate replacement rate, $b_{t+1}$, expressed in equation 2.14 .

In addition to a more sustainable public pension system after the reform, lifetime utility of households is also higher in the reform case. Figure 4.14 shows the CEV for cohorts entering the labor market at the time indexed on the horizontal axis. The vertical axis shows the percentage of lifetime consumption that a household would be given in the baseline scenario to be as well off as in the reform scenario. Positive values, therefore, denote that cohorts in the reform case are better off than in the baseline scenario. 
Looking at welfare implications in detail, Figure 4.14 reveals that households are better off in the reform scenario than in the baseline case by up to $1.4 \%$. This means that one would have to give them $1.4 \%$ of aggregate lifetime consumption in the baseline scenario to make them indifferent to the reform case. This maximum value holds for cohorts entering the labor market around the year 2028 since they fully profit from lower contributions and a higher replacement rate. Earlier cohorts profit less since they are only influenced by the reform during part of their lives.

Figure 4.14 - Consumption equivalent variation

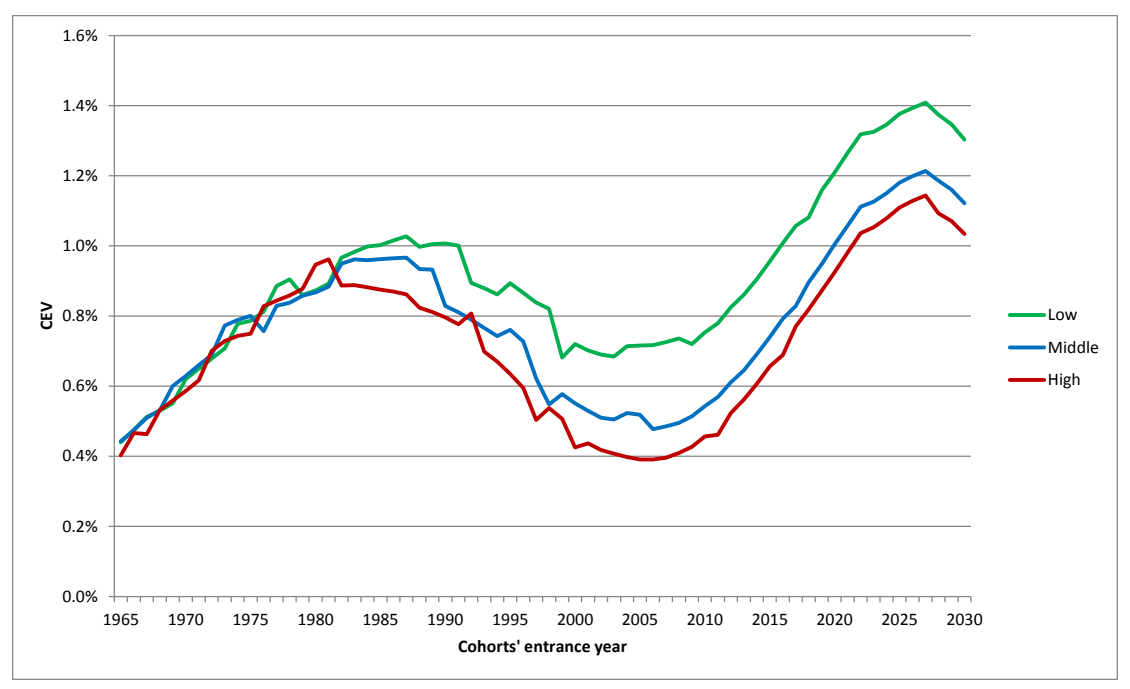

Source: own calculations.

Furthermore, high skill groups entering the labor market after 1980 seem to profit less from the higher adjustment rates than their low skill counterparts. The reason stems from the fact that younger low skilled cohorts retire much earlier than the statutory eligibility age (see Figure 4.7). Therefore, they are punished more by higher deductions than their high skill counterparts, who always retire late. For cohorts entering the labor market in later years, this negative effect for low skill groups diminishes because even these cohorts start to retire later (general upward trend in retirement ages). From this point onward, low skill households profit more from the reform than high skill groups. And the benefit will again be more than proportional because the increase in their pension benefits represent a proportionally larger increase in income than for the high skilled. This gap in CEVs will contribute to a substantial decrease in the inequality gap between groups. In comparison to all reforms, this is the only one where inequality shrinks substantially for all cohorts, both in the short and long run.

\subsection{Hybrid DB/DC vs. defined benefits}

The presence of a hybrid DB/DC mechanism leads to an automated adjustment of pension benefits to demographic trends and the evolution in wage growth (see equation 2.14), as described 
in detail above. The aim is to make the PAYG pension system more sustainable by sharing the burden of an aging population between generations without requiring politics to constantly intervene. As can be seen above in equation (2.14), the aging of the population leads to a fall in the replacement rate. In politics, this circumstance is sometimes seen as worrisome because it is feared that pension benefits will not suffice to finance a minimum standard of living for specific population groups. Therefore, there are recurring policy proposals to hold the replacement rate constant, which implicitly means to return to a defined benefit regime. In order to study these proposals and understand the long-run effects, we simulate a reform proposal that holds the replacement rate constant from the year 2017 onward until 2045. To set the replacement rate constant means to let the contribution rates adjust endogenously to finance the PAYG pension system. After 2045, we assume that the original replacement rate following equation 2.14 will be in place again.

Figure 4.15 - Contribution rates

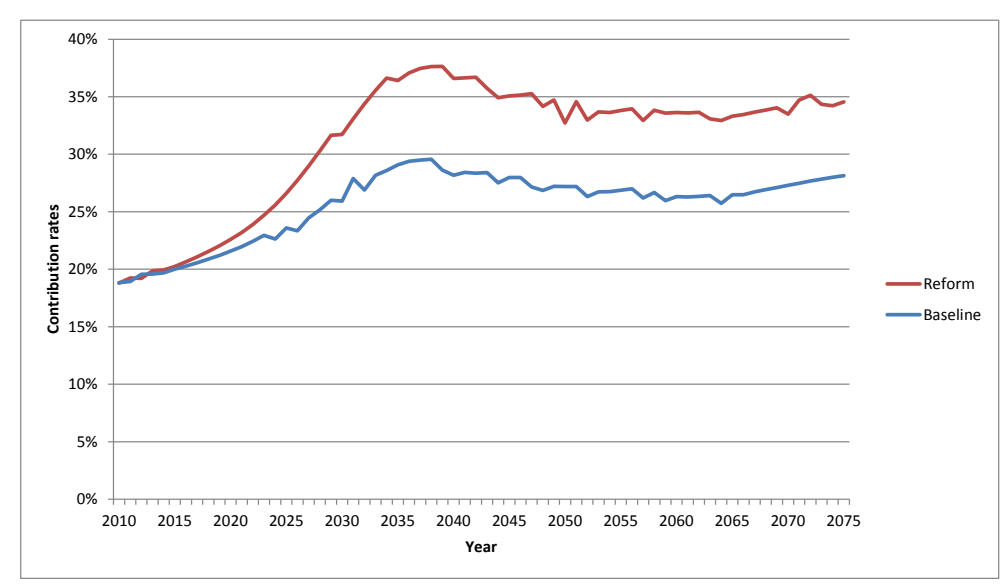

Source: own calculations.

Figure 4.15 compares the contribution rates under a regime with a replacement rate in place (baseline) and a regime with a constant replacement rate (reform). The difference is striking. While contribution rates to the pension system stabilize in the long run around $27 \%$ in the baseline case, they do so around 34\% in the reform scenario and stay at this elevated level afterwards. This pronounced difference in contributions has major implications on labor supply and especially on retirement ages (see Figure 4.16). 
Figure 4.16 - Retirement ages

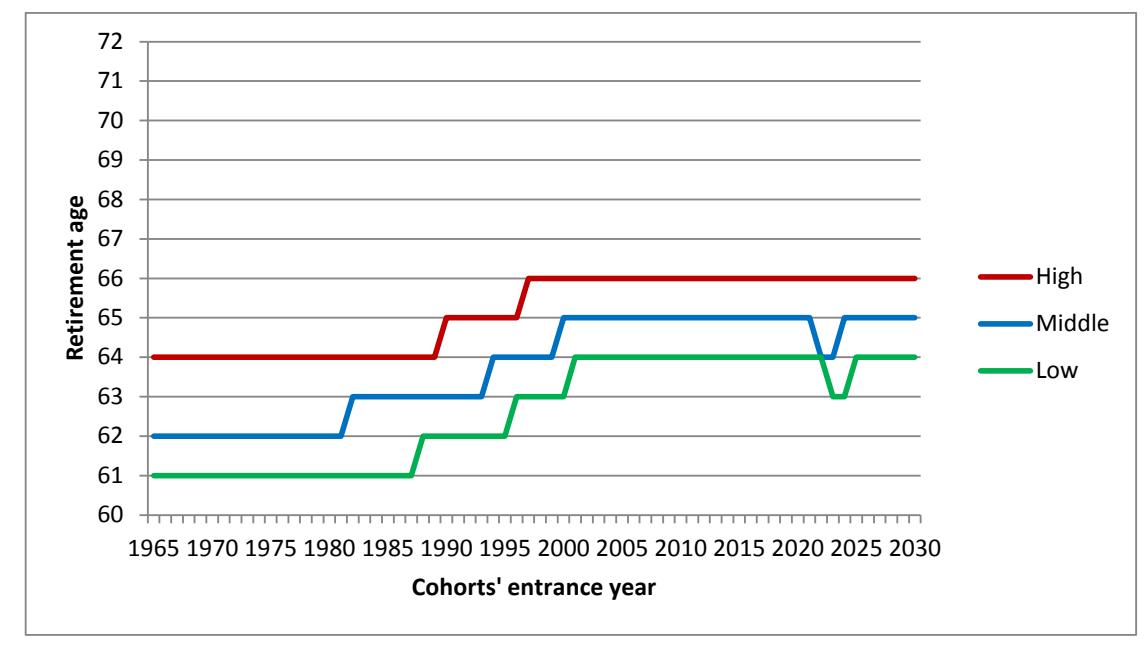

Source: own calculations.

Indeed, the major observation is that agents always retire earlier in the reform scenario. This effect is amplified for later cohorts since they are affected more by the reform. There are two arguments that explain this behavior. First, because of the elevated contribution rates, households want to leave the pension system by retiring earlier. Second, they can afford to do so since pension benefits are larger due to a high replacement rate. This creates a vicious circle that reinforces the impact of the reform. A fixed replacement rate implies increasing contribution rates due to population aging. Households change their retirement decision and retire earlier (see Figure 4.16 and Figure 4.17). The lower number of contributors to the PAYG pension system again leads to a further rise in the contribution rate to balance the system, which starts another circle until the equilibrium is reached. As a consequence, households retire substantially earlier. 
Figure 4.17 - Retirement ages (differences)

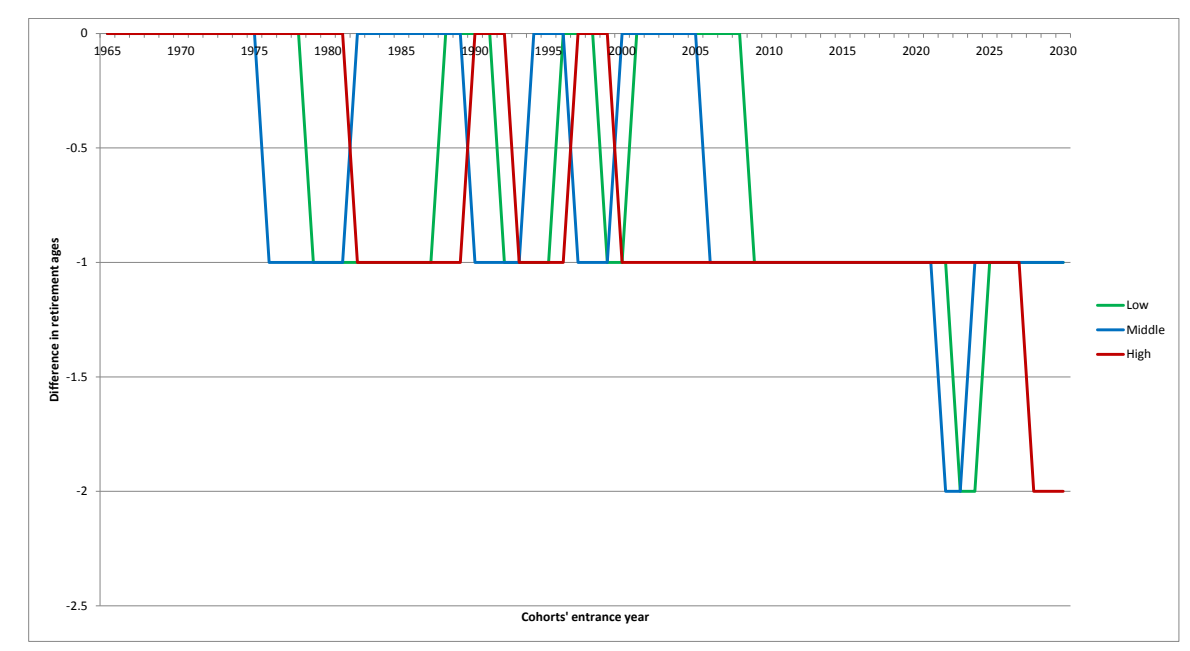

Source: own calculations.

Figure 4.17 shows the difference in retirement ages for different cohorts and skill groups between the reform and the baseline scenario. Negative values mean that retirement ages are lower in the reform than in the baseline scenario. It shows that the effect is more pronounced for the middle and highest skill group. Since we do not allow for retirement earlier than the age of 60, low skill groups, which already retire early in the baseline case, are constrained in their retirement decision. Higher skill groups, which generally retire later, however, can adjust their retirement ages accordingly since they are less restricted in the baseline scenario.

The question that arises is which cohort benefits/suffers the most from the hypothetical reform. Figure 4.18 displays the CEV for different cohorts.

Figure 4.18 - Consumption equivalent variation

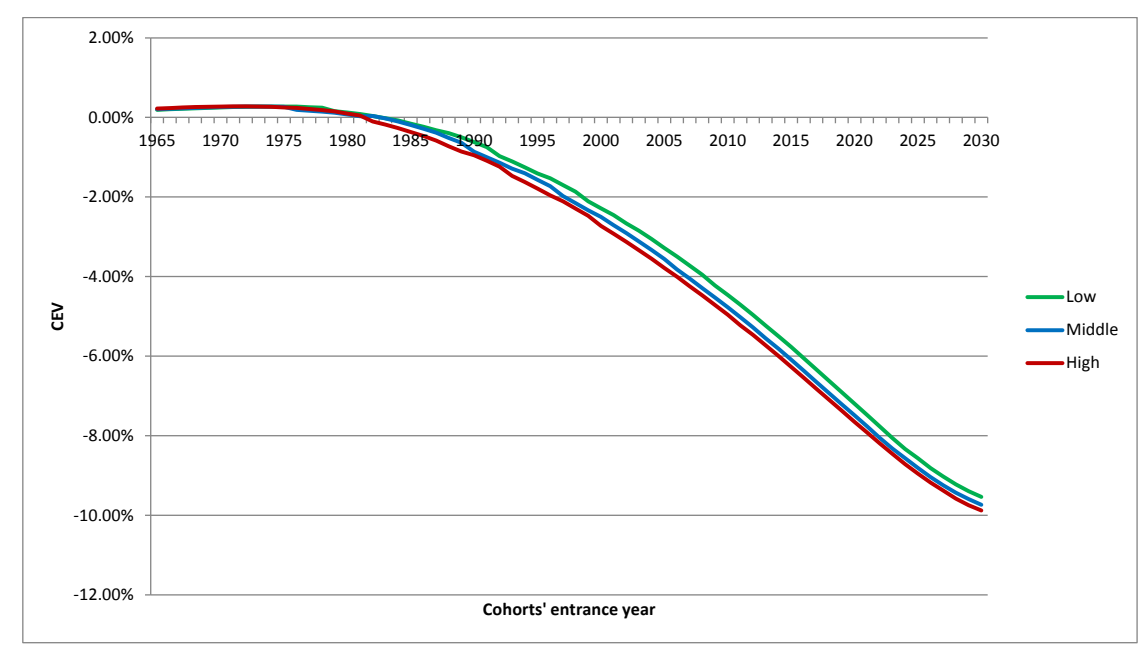

Source: own calculations.

Cohorts entering the labor market in early years gain from this reform since they receive higher pension benefits without paying higher contributions. This shows that the effects of policies 
directed toward older voters have a significant impact on intergenerational inequality of transfers. The main price paid for these actions is a significant decrease in the comparative welfare of the young generations that will have to contribute much more to guarantee the sustainability of the system. In fact, cohorts entering in later years are always much worse off. Those entering in 2030 are $10 \%$ worse off than their counterparts in the baseline scenario in terms of lifetime consumption. In short, and not surprisingly, younger cohorts, who have to finance the reform, are the biggest losers.

Examining the distributional effects reveals that the highest skill group is slightly more harmed by the reform. Elevated contribution rates are harmful for all groups and incentivize them to retire earlier. However, the welfare impact is larger for the high skill group because these individuals have a higher loss from earnings. They relinquish higher wages in later stages in life for a pension and at the same time this pension is calculated with a lower adjustment factor. In contrast, low skilled individuals have to relinquish a lower wage and receive a pension that is calculated for an adjustment factor that is already smaller than one. According to our results, the former effect is stronger than the latter and therefore we see that the low skilled group loses slightly less welfare than the high skilled. This implies that the inequality gap between groups tends to contract, leading to greater welfare equality between them, although on a much lower welfare level.

\subsection{Unified framework for reform comparisons}

According to the previous results for each policy reform, this section provides a unified overview of the previous reforms (proposals) and ranks them according to different outcome variables (see Table 4.2). The findings for the reform where the retirement age is increased to 67 and the actuarial neutral reform are in line with previous research. This further confirms this paper's results and reassures the consistency of our model with respect to each reform evaluation. As a central contribution of this study, our model allows for a unified framework to compare different reform proposals and provides valuable policy recommendations. Table 4.2 summarizes and compares the effects of each reform with the benchmark scenario. For retirement ages and CEVs, cohorts entering the labor market between 1995 and 2005 are considered as examples. The columns "Retirement ages" and "Gap in CEVs" give the maximum and minimum differences in retirement ages and gaps in CEVs across skill groups between the reform and baseline scenarios, respectively. The column "Utility" shows the range of the 10 year averages for the three skill groups. For the contribution and replacement rates, we compare the 10 year averages for the time range 2040-2050. These later years are chosen because they correspond to the years when the 1995-2005 cohorts retire. 
Table 4.2 - Summary results

\begin{tabular}{|c|c|c|c||}
\hline \hline $\begin{array}{c}\text { Reform } \\
\text { proposal }\end{array}$ & Retirement ages & $\begin{array}{c}\text { Utility (CEV } \\
\text { in \%) }\end{array}$ & $\begin{array}{c}\text { Gap in CEVs } \\
\text { between the lowest } \\
\text { and highest group } \\
\text { (in p.p.) }\end{array}$ \\
\hline $\begin{array}{c}\text { Increase of } \\
\text { SRA to 67 }\end{array}$ & 0 to 1 & 0.8 to 0.9 & -0.0 to 0.1 \\
\hline $\begin{array}{c}\text { Actuarial } \\
\text { neutral }\end{array}$ & 1 to 3 & 0.5 to 0.8 & 0.2 to 0.3 \\
\hline $\begin{array}{c}2: 1 \\
\text { reform }\end{array}$ & 2 to 3 & 1.5 to 1.7 & 0.1 to 0.2 \\
\hline $\begin{array}{c}\text { Constant } \\
\text { replacement } \\
\text { rate }\end{array}$ & -1 to 0 & -2.3 to -2.7 & 0.4 to 0.5 \\
\hline
\end{tabular}

\begin{tabular}{||c|c|}
\hline $\begin{array}{c}\text { Contribution } \\
\text { rates (in p.p.) }\end{array}$ & $\begin{array}{c}\text { Replacement } \\
\text { rates (in p.p.) }\end{array}$ \\
\hline-2.0 & 1.5 \\
\hline-0.5 & 3.4 \\
\hline-3.5 & 3.0 \\
\hline 7.5 & \\
\hline
\end{tabular}

Note: Time range with respect to cohorts' entry years: 1995-2005.

Time range: $2040-2050$.

Source: own calculations.

When looking at the decisions on retirement ages, the 2:1 reform scenario exhibits the largest impact (2-3 years later retirement). This reform is followed by the actuarial neutral reform with around 1-3 years of postponed retirement and the 67 reform by 1 year. A negative change of 1 year can be observed in the constant replacement rate reform.

Interpreting lower contribution rates and a higher replacement rate as measures of sustainability of the public pension system, the following picture emerges: The 2:1 reform shows the largest fall in contribution rates (-3.5 p.p.) followed by the 67 reform (-2.0 p.p.) and the actuarial neutral reform (-0.5 p.p.). The largest raise in replacement rate can be found in the actuarial neutral reform (3.4 p.p.) and the 2:1 reform (3.0 p.p.). The 67 reform still achieves an increase of 1.5 p.p. Only the reform proposal which holds the replacement rate constant severely harms the public pension system through soaring contribution rates of 7.5 p.p. Therefore, in terms of sustainability, the 2:1 reform is the most beneficial reform proposal, whereas holding the replacement rate constant is the most harmful one.

The main mechanism that drives our welfare results are contribution rates: as soon as a reform leads to declining contribution rates as a direct effect, this diminishes the labor disincentives of working. As a consequence, agents are less constrained and work more which further drives down the contribution rates. In this sense, some reforms potentially have larger welfare effects. In terms of the CEV, again the 2:1 reform is the most beneficial reform. Here, agents are up to $1.7 \%$ better off. This reform is followed by the 67 reform (up to $0.9 \%$ ) and the actuarial neutral reform (up to 
0.8\%). The reform that keeps the replacement rate constant is again the most damaging one: Agents are up to $2.7 \%$ worse off than in the baseline scenario.

All these reforms have consequences for the inequality between skill groups. The inequality tends to shrink in all scenarios except for the first reform scenario (increase of SRA to 67). Paradoxically, the one with the highest equality gains is the one that in welfare level terms leaves everyone worse off (constant replacement rate reform). Excluding this reform, we observe that the actuarial neutral reform is the one contributing the most for equality. The 2:1 reform follows closely but it cannot be forgotten that for cohorts in the long run this effect fades out. The 67 reform has almost no impact on inequality. Consequently, the former two reforms would be the ones to be considered when the main target of policy is to decrease inequality.

\section{Performance of reforms under different macroeconomic regimes}

After examining the impact of each reform independently and looking at its effects, we test how these same reforms would perform under different, extreme, macroeconomic regimes. The main objective is to observe whether each reform has a similar or very different behavior according to the macroeconomic environment in which they are implemented. Therefore, we choose a low interest rate and low growth regime, since in our benchmark regime both interest rates and growth are in line with what has been observed in the last decades in several countries. Since the financial crisis and the slowdown in technology growth in the last few years have affected several developed countries, it is important to test if the impact of the reforms that have been proposed in the literature or in the public space, which are explored in this paper, would survive under these extreme conditions. In an overall perspective we can be confident that in any regime where the reforms proposed are implemented, the impact of these will remain the same. This reassures the worthiness of implementing some of these reforms. At the same time, other reforms that have a significant negative impact both in the sustainability of pension systems and in the welfare of individuals should be avoided.

\subsection{Low-interest-rate regime}

The world interest rates have been decreasing in recent years due to the expansionary monetary policy of central banks. Especially in the Euro-zone, the decrease has been very pronounced and real interest rates are currently close to zero or even negative for some countries. This development certainly has impacts on capital income of savers and triggers changes in saving decisions of households. In order to simulate such a regime of low interest rates, we introduce a wedge between the marginal product of capital and real interest rates in our model. Still, we want 
interest rates to be connected to capital productivity and its general evolution. Therefore, we introduce the wedge that is modeled as a fraction of the marginal product of capital. Another interpretation could be a linear capital tax of $26.4 \%$, as is assumed in Fehr et al. (2013). This tax will drive a wedge between the marginal productivity of capital and the interest rate perceived by the households. To mimic the developments in interest rates since the recent financial crisis, we assume that the wedge increases linearly during the period 2008-2016 and stays at this level afterwards.

In general equilibrium, several effects are at work. As a first round effect, agents reduce their savings due to lower returns on savings. This, in turn, reduces the capital stock, which is the sum of aggregate savings (in this closed economy setting). Holding labor constant, a smaller capital stock implies a higher marginal productivity of capital. This increases the net interest rate, namely the one perceived by the households. In general equilibrium, this effect leads to the outcome that the net interest rate is only slightly different from the case without a wedge. However, it is important to note that aggregate savings are substantially lower than in the benchmark scenario. This observation again has consequences on retirement decisions.

Table 5.1 evaluates, parallel to Table 4.2, the reforms described in previous chapters under this low interest regime. It compares the reform scenario vis-à-vis its baseline scenario. Note that we cannot directly compare both tables 4.2 and 5.1 in level terms. Instead, we will emphasize the degree of impact and how each reform performs and ranks in terms of the specific variables of interest in the analysis. In Table 5.1 it is important to remember that, contrary to the benchmark regime, all scenarios exhibit lower interest rates. 
Table 5.1 - Low interest rates

\begin{tabular}{|c|c|c|c|||c|c|}
\hline \hline $\begin{array}{c}\text { Reform } \\
\text { proposal }\end{array}$ & Retirement ages & $\begin{array}{c}\text { Utility (CEV } \\
\text { in \%) }\end{array}$ & $\begin{array}{c}\text { Gap in CEVs } \\
\text { between the lowest } \\
\text { and highest group } \\
\text { (in p.p.) }\end{array}$ & $\begin{array}{c}\text { Contribution } \\
\text { rates (in p.p.) }\end{array}$ & $\begin{array}{c}\text { Replacement } \\
\text { rates (in p.p.) }\end{array}$ \\
\hline $\begin{array}{c}\text { Increase of } \\
\text { SRA to 67 }\end{array}$ & -1 to 2 & 0.1 & -0.1 to 0.2 & -2.0 & 1.5 \\
\hline $\begin{array}{c}\text { Actuarial } \\
\text { neutral }\end{array}$ & 1 to 4 & -0.2 to 0.2 & 0.2 to 0.5 & -0.6 & 2.6 \\
\hline $\begin{array}{c}2: 1 \\
\text { reform }\end{array}$ & 1 to 3 & 0.8 to 1.0 & 0.2 to 0.4 & -3.4 & 2.8 \\
\hline $\begin{array}{c}\text { Constant } \\
\text { replacement } \\
\text { rate }\end{array}$ & -2 to 0 & -3.0 to -3.5 & 0.5 to 0.6 & & \\
\cline { 1 - 3 }
\end{tabular}

Note: Time range with respect to cohorts’ entry years: 1995-2005.

Time range: $2040-2050$.

Source: own calculations.

As a general outcome, households react stronger in their retirement behavior under the lowinterest-rate regime: the variation in retirement age is higher for all reforms in both the positive and negative directions. For instance, households retire up to 4 years later when the 2:1 reform is implemented, while before it was at most 3 years later. As a result, the relative ranking slightly changes since now the actuarial neutral and the 2:1 reform have a similar impact on retirement behavior.

Contribution rates react similarly to the regime with high interest rates. Changes in replacement rates, in contrast, are smaller than before. This is due to lower growth of wages under the lowinterest-rate regime. In contrast to the benchmark regime, the 2:1 reform now leads to the highest relative change in replacement rates as compared to the actuarial neutral reform, which previously showed the highest relative increase. Since households benefit from a similar relative reduction in contribution rates as in the high interest rate regime and the rise in replacement rates is relatively lower, the gains from reforms in terms of welfare will be lower. In terms of welfare gains, the relative ranking between reforms remains the same as in the benchmark regime.

Concerning the gap in CEVs, representing how households differently benefit from reforms, we observe a general increase and variation for all reforms. This means that low skilled households benefit disproportionally more from reforms under the low interest rate than in the high interest rate regime. This stems from higher relative gains in income due to the increase in the extensive margin of labor supply. Since low skilled households have lower income compared to the high 
skilled households, any additional gain in work income from reforms leads to a disproportional increase in consumption and welfare in comparison to the high skilled. This effect is strengthened when interest rates are lower because capital gains are smaller in this regime and any marginal increase in labor income is more beneficial for low skilled households than for the high skilled counterparts.

\subsection{Low growth of technology regime}

The possibility that developed countries are entering an age of low technological and economic growth has been advanced over the last decade. The so called secular stagnation will prevail in the next decades and developed economies will face the slowest growth rates of the last half of a century, according to Gordon (2014) and Fernald (2015). This, of course, brings more challenges to pension systems and to their reforms, as the effects may differ in intensity and rank differently between reforms.

In order to simulate such an environment of low economic growth, we define a lower growth rate of technology that will affect production as well as wages and capital rates of return. Therefore, labor productivity growth is set to $g=0.5 \%$, a very extreme low growth environment in comparison with our benchmark case where $g=1.5 \%$. Comparing to the benchmark regime, in general equilibrium, several effects are at work. As a first round effect, ceteris paribus, lower technology growth produces lower output. This will produce feedback effects that lead agents to work more hours to earn more and will also increase savings in order to raise capital and, hence, production. This increases the capital stock relative to output, which is the sum of aggregate savings (in this closed economy setting). Raising capital stocks will reduce returns on capital and improve returns to labor in our model.

Note that individuals, when planning their life-cycle decisions, already take into account that this low growth setting will remain through time. This, of course, influences the comparisons of reforms to the baseline case (low growth environment and no reform), since a low growth perspective will be a consideration in the decisions of agents. Namely, individuals tend to retire on average one year later compared to the benchmark environment (for some cohorts, decisions remain equal), although the net effect on contribution rates and replacement rates tends to be quite constant between environments. Individuals take the decision of later retirement due to the need of compensating for lower interest rates that affect consumption and welfare levels. These effects have to be taken into account when observing the effects of each reform. As stated above, we cannot directly compare tables 4.2 and 5.2 in level terms, so instead we will emphasize the degree of impact of each reform. 
A change in regime that stems from changes in technological growth must only have level effects on our outcomes since technological growth should not impact the decision of households. As an overall inspection of the results (see Table 5.2), the impact of each reform on the several variables is identical to the ones observed in the high growth regime (benchmark regime), which confirms our expectations. Therefore, we find that the effects of the implementation of all reforms on the pension system lead to a similar variation of retirement ages. As for pension system components, the actuarial neutral reform produces a slight increase in replacement rates, which is responsible for a higher increase in welfare for this reform. The other reforms show equal findings to the high growth regime. Concerning contribution rates, only the increase of the statutory retirement age to 67 produces a less positive impact of the reform. This is mirrored by the welfare gains, which are lower in comparison to the high growth regime. All other reforms do not affect contribution rates in a way that is different from the benchmark regime. Consequently, the same holds for welfare increase and gaps in CEVs between skill groups.

Table 5.2 - Low technological growth

\begin{tabular}{|c|c|c|c||}
\hline \hline $\begin{array}{c}\text { Reform } \\
\text { proposal }\end{array}$ & Retirement ages & $\begin{array}{c}\text { Utility (CEV } \\
\text { in \%) }\end{array}$ & $\begin{array}{c}\text { Gap in CEVs } \\
\text { between the lowest } \\
\text { and highest group } \\
\text { (in p.p.) }\end{array}$ \\
\hline $\begin{array}{c}\text { Increase of } \\
\text { SRA to 67 }\end{array}$ & 0 to 1 & 0.7 & -0.1 to 0.1 \\
\hline $\begin{array}{c}\text { Actuarial } \\
\text { neutral }\end{array}$ & 1 to 3 & 1.3 to 1.5 & 0.1 to 0.3 \\
\hline $\begin{array}{c}2: 1 \\
\text { reform }\end{array}$ & 1 to 3 & 1.5 to 1.6 & 0.1 to 0.2 \\
\hline $\begin{array}{c}\text { Constant } \\
\text { replacement } \\
\text { rate }\end{array}$ & -1 to 0 & -2.2 to -2.6 & 0.3 to 0.5 \\
\hline
\end{tabular}

Note: Time range with respect to cohorts' entry years: 1995-2005.

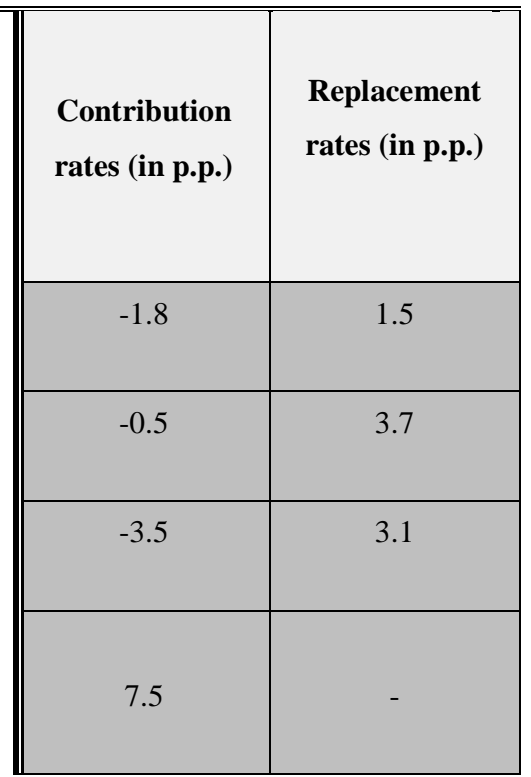

Time range: $2040-2050$.

Source: own calculations.

\section{Conclusion}

In order to assess the suitability of pension reforms to ensure the sustainability of pension systems, we built an OLG model that allows for an evaluation of various reforms within a unified framework. A special focus of our analysis is on retirement ages and their interactions with macroeconomic indicators in the face of demographic change. We simulated different reforms and 
compared the outcomes to a pre-defined baseline scenario. This baseline scenario reflects early retirement of households as observed in the data: during the given age interval of 60-70, agents retire between the ages of 60 and 65. This mimics the German public pension system, which produces incentives for early retirement, mainly due to low deductions. Furthermore, we observe some heterogeneity in retirement ages between skill groups: agents from low skill groups tend to retire earlier than those from high skill groups.

Our reform simulations gave valuable insights: Our simulation with actuarial neutral adjustment rates led to beneficial effects for the PAYG pension system. In this scenario, households work longer, taking pressure off the pension system's budget equation. This results in lower contributions and higher pension levels despite demographic change. In terms of welfare measures, households are better off under this reform than in the baseline scenario and the welfare gap narrows between skill groups. Another reform proposal that abolishes the dynamics of the replacement rate and holds it constant at its 2017 level shows reverse results: contribution rates would have to rise by roughly 6 p.p. to balance the pension system's budget equation. In this case, households retire much earlier due to the inflated size of the pension system. In contrast, connecting the statutory eligibility age to the rise in life expectancy in an automatic way (2:1 reform) has very beneficial effects for contribution rates and the replacement rate. In detail, we hereby assume an increase in the statutory eligibility age by 2 years for every 3 years of additional life expectancy. This allows the contribution rate to fall by up to 3 p.p. relative to the baseline scenario and the replacement rate to stabilize around a level of 50\%. Additionally, different assumptions for macroeconomic regimes like low interest rates and low technological growth show that all reforms perform similarly, independent of the macroeconomic regime. In terms of welfare, the reforms provide a larger improvement for all skill groups (or smaller deterioration in the case of the constant replacement rates reform), which stresses the importance of these reforms in every economic context.

In conclusion, our study sheds some light on the interaction of pension reforms, labor supply reactions to them, and the macroeconomic environment. Incentives created by the pension system are discussed in detail to understand the mechanisms through which reforms affect people's labor supply and savings behavior. Results suggest that it is essential for researchers and policy makers to understand the incentives created by the pension system and reactions of households to changes in those incentives. Actual retirement behavior is indeed a key variable for evaluating the suitability of reforms to insure the sustainability of pension systems. Possible feedback effects also have to be considered to avoid imbalances in the pension system and an underestimation of the quantitative effects of pension reforms. 


\section{References}

Altig, D. et al., 2001. Simulating fundamental tax reform in the United States. American Economic Review, 91(3), pp. 574-595.

Angeletos, G. et al., 2001. The hyperbolic consumption model: Calibration, simulation, and empirical evaluation. Journal of Economic Perspectives, 15(3), pp. 47-68.

Auerbach, A. \& Kotlikoff, L., 1987. Dynamic Fiscal Policy. Cambridge: Cambridge University Press.

Bansal, R. \& Yaron, A., 2004. Risks for the long run: A potential resolution of asset pricing puzzles. The Journal of Finance, Volume 4, pp. 1481-1509.

Beetsma, R., Bettendorf, L. \& Broer, P., 2003. The budgeting and economic consequences of ageing in the Netherlands. Economic Modelling, 20(5), pp. 987-1013.

Beetsma, R., Bettendorf, L. \& Broer, P., 2003. The budgeting and economic consequences of ageing in the Netherlands. Economic Modelling, pp. 987-1013.

Blundell, R. \& Emmerson, C., 2007. Fiscal Effects of Reforming the UK State Pension System. In: J. Gruber \& D. Wise, eds. Social Security Programs and Retirement Around the World: Fiscal Implications of Reform. Washington D.C.: s.n.

Blundell, R., French, E. \& Tetlow, G., 2017. Retirement Incentives and Labor Supply. In: J. Piggott \& A. Woodland, eds. Handbook of Population Aging. s.l.:Elsevier, pp. 455-566.

Boeri, T., Garibaldi, P. \& Moen, E., 2016. A Clash of Generations? Increase in Retirement Age and Labor Demand For Youth. CEPR Discussion Papers 11422.

Börsch-Supan, A., 2004. Faire Abschläge in der gesetzlichen Rentenversicherung. Sozialer Fortschritt, pp. 258-261.

Börsch-Supan, A., 2005. From traditional DB to notional DC systems: The pension reform process in Sweden, Italy and Germany. Journal of the European Economic Association, Volume 3, pp. 458-465.

Börsch-Supan, A., 2007. Rational Pension Reform. The Geneva Papers, Volume 32, pp. 430446. 
Börsch-Supan, A., Bucher-Koenen, T., Kutlu-Koc, V. \& Goll, N., 2017a. Dangerous FlexibilityRetirement Reforms Reconsidered. MEA Discussion Paper.

Börsch-Supan, A., Härtl, K. \& Leite, D., 2017b. Earnings test, (non)-actuarial adjustments and flexible retirement. MEA Discussion Papers.

Börsch-Supan, A., Härtl, K. \& Leite, D., 2018. Who cares about the day after tomorrow? Pension issues when households are time inconsistent. Review of Development Economics, forthcoming.

Börsch-Supan, A., Härtl, K. \& Leite, D. N., 2017c. Labor supply, retirement decisions and incentives created by social insurance. Handbook of the Economics of Population Aging. s.l.: Elsevier, Amsterdam, pp. 781-864.

Börsch-Supan, A., Härtl, K. \& Ludwig, A., 2014. Aging in Europe: Reforms, international diversification, and behavioral reactions. American Economic Review P\&P, Volume 5, pp. $224-$ 229.

Börsch-Supan, A. \& Schnabel, R., 1998. Social security and declining labor-force participation in Germany. The American Economic Review P\&P, 88(2), pp. 173-178.

Börsch-Supan, A. \& Stahl, K., 1991. Household saving and consumption constraints. Journal of Population Economics, pp. 233-255.

Börsch-Supan, A. \& Weiss, M., 2016. Productivity and age: Evidence from work teams at the assembly line. The Journal of the Economics of Ageing, Voume 7, pp. 30-42.

Börsch-Supan, A. \& Wilke, C., 2005. The German Public Pension System: How it Will Become an NDC System Look-Alike. In: R. Holzmann \& E. Palmer, eds. Pension Reform Issues and Prospects for Non-Financial Defined Contribution (NDC) Schemes. Washington, DC: The World Bank.

Browning, M., Hansen, L. \& Heckman, J. J., 1999. Micro Data and General Equilibrium Models. In: J. Taylor \& M. Woodford, eds. Handbook of Macroeconomics. s.l.: Elsevier Science B.V., pp. 543-633.

Casanova, M., 2013. Revisiting the Hump-Shaped Wage Profile: Implications for Structural Labor Supply Estimation. University of California, Los Angeles.

Catalan, M., Guajardo, J. \& Hoffmaister, A., 2010. Coping with Spain’s aging: Retirement rules and incentives. Journal of Pension Economics and Finance, pp. 549-581. 
Catalan, M., Guajardo, J. \& Hoffmaister, A. W., 2010. Coping with Spain’s aging: Retirement rules and incentives. Journal of Pension Economics and Finance, 9(4), pp. 549-581.

Chan, S. \& Stevens, A. H., 2008. What you don’t know can’t help you: Pension knowledge and retirement decision making. Review of Economics and Statistics, 90(2), pp. 253-266.

Cogan, J., 1981. Fixed costs and labour supply. Econometrica, Volume 4, pp. 945-963.

Coile, C., 2004. Retirement incentives and couples' retirement decisions. Topics in Economic Analysis \& Policy, Volume 4(1), pp. 1-28.

Desmet, R. \& Jousten, A., 2003. The decision to retire: Individual heterogeneity and actuarial neutrality. Centre for Economic Policy Research.

Deutsche Rentenversicherung Bund, 2015a. Die richtige Altersrente für Sie. Deutsche Rentenversicherung Bund.

Deutsche Rentenversicherung Bund, 2015b. Rentenversicherung in Zeitreihen. DRV-Schriften.

Diamond, P. \& Köszegi, B., 2003. Quasi-hyperbolic discounting and retirement. Journal of Public Economics, Volume 87, p. 1839-1872.

Duggan, M., Singleton, P. \& Song, J., 2007. Aching to retire? The rise in the full retirement age and its impact on the social security disability rolls. Journal of Public Economics, Volume 91, pp. 1327-1350.

Eisensee, T., 2006. Essays on Public Finance: Retirement Behavior and Disaster Relief. Stockholm: Institute for International Economic Studies, Stockholm University.

Eurostat, 2010. Mortality and life expectancy statistics. http://ec.europa.eu/eurostat/statisticsexplained/index.php/Mortality_and_life_expectancy_statistics.

Fehr, H., Kallweit, M. \& Kindermann, F., 2012. Pension reform with variable retirement age: A simulation analysis for Germany. Journal of Pension Economics \& Finance, 11(3), pp. 389-417.

Fehr, H., Kallweit, M. \& Kindermann, F., 2013. Should pensions be progressive? European Economic Review, Volume 63, pp. 94-116.

Fernald, J. G., 2015. Productivity and potential output before, during, and after the Great Recession. NBER Macroeconomics Annual Annual 2014, Volume 29, pp. 1-51. 
Findley, T. S. \& Caliendo, F. N., 2015. Time inconsistency and retirement choice. Economics Letters, Volume 129, pp. 4-8.

Fisher, W. \& Keuschnigg, C., 2010. Pension reform and labor market incentives. Journal of Population Economics, 23(2), pp. 769-803.

Frederick, S., Loewenstein, G. \& O'Donoghue, T., 2002. Time discounting and time preference: A critical review. Journal of Economic Literature, 40(2), pp. 351-401.

French, E., 2005. The effects of health, wealth, and wages on labour supply and retirement behaviour. Review of Economic Studies, 72(2), pp. 395-427.

Fullerton, D. \& Rogers, D., 1993. Who Bears the Lifetime Tax Burden? Washington D.C.: Brookings Institution Press.

Fuster, L., Imrohoroglu, A. \& Imrohoroglu, S., 2003. A welfare analysis of social security in a dynastic framework. International Economic Review, 44(4), pp. 1247-1274.

Gasche, M., 2012. Alte und neue Wege zur Berechnung der Rentenabschläge. MEA Discussion Papers.

Gasche, M., 2012. Was sind die richtigen Rentenabschläge? - Neue Perspektiven. Jahrbuch für Wirtschaftswissenschaften, pp. 187-235.

Gordon, R. J., 2014. The Demise of U.S. Economic Growth: Restatement, Rebuttal, and Reflections. NBER Working Paper Nr. 19895.

Graf, N., Hofer, H. \& Winter-Ebmer, R., 2011. Labour supply effects of a subsidized old-age part-time scheme in Austria. Zeitschrift für Arbeitsmarktforschung, Volume 44, pp. 217-229.

Gruber, J. \& Wise, D., 1999. Social Security and Retirement around the World. Cambridge, Massachusetts: NBER Books.

Gruber, J. \& Wise, D., 2005. Social security programs and retirement around the world: Fiscal implications, introduction and summary. NBER Working Paper Nr. 11290.

Gustman, A. L. \& Steinmeier, T. L., 2004. Social security, pensions and retirement behaviour within the family. Journal of Applied Econometrics, Volume 19, p. 723-737.

Gustman, A. L. \& Steinmeier, T. L., 2005. The social security early entitlement age in a structural model of retirement and wealth. Journal of Public Economics, Volume 89, p. 441-463. 
Hanel, B. \& Riphahn, R., 2012. The timing of retirement - new evidence from Swiss female workers. Labour Economics, 19(5), pp. 718-728.

Huber, M., Lechner, M. \& Wunsch, C., 2013. The Effect of Firms' Partial Retirement Policies on the Labour Market Outcomes of their Employees. CEPR Discussion Paper No. DP9574.

Huggett, M., Ventura, G. \& Yaron, A., 2011. Sources of lifetime inequality. American Economic Review, 101(7), pp. 2923-2954.

Human Mortality Database, 2016. University of California, Berkeley (USA) and Max Planck Institute for Demographic Research (Germany). [Online]

Available at: www.humanmortality.de

Kallestrup-Lamp, M., Rosenskjold C., 2017. Insight into the Female Longevity Puzzle: Using Register Data to Analyse Mortality and Cause of Death Behaviour Across Socio-economic Groups, CREATES Research Paper 2017-8.

Kotlikoff, L., Smetters, K. A. \& Walliser, J., 2007. Mitigating America's demographic dilemma by pre-funding social security. Journal of Monetary Economics, 54(2), pp. 247-266.

Laibson, D., 1998. Life-cycle consumption and hyperbolic discount functions. European Economic Review, Volume 42, pp. 861-871.

Ludwig, A., 2007. The Gauss-Seidel-quasi-Newton method: A hybrid algorithm for solving dynamic economic models. Journal of Economic Dynamics \& Control, 31(5), pp. 1610-1632.

OECD, 2015. Pensions at a Glance. Paris: OECD.

Palmer, E., 2000. The Swedish Pension Reform Model: Framework and Issues. Social Protection Discussion Paper No. 12, The World Bank, Washington, DC.

Queisser, M. \& Whitehouse, E., 2006. Neutral or Fair? Actuarial Concepts and Pension-System Design. OECD Social, Employment and Migration Working Papers No. 40.

Rogerson, R. \& Wallenius, J., 2013. Nonconvexities, retirement, and the elasticity of labor supply. American Economic Review, 103(4), pp. 1445-1462.

Sánchez-Martín, A. R., 2010. Endogenous retirement and public pension system reform in Spain. Economic Modelling, Volume 27, pp. 336-349.

Social Security Administration, 2014. Social Security Programs Throughout the World: Europe. SSA Publication No. 13-11801, Washington D.C. 
Sonnet, A., Olsen, H. \& Manfredi, T., 2014. Towards More Inclusive Ageing and Employment Policies: The Lessons from France, The Netherlands, Norway and Switzerland. The Economist, Volume 162, pp. 315-339.

Thanopoulos, A. C. \& Kumru, Ç. S., 2008. Social security and self control preferences. Journal of Economic Dynamics \& Control, Volume 32, p. 757-778.

van der Klaauw, W. \& Wolpin, K. I., 2008. Social security and the retirement and savings behavior of low-income households. Journal of Econometrics, Volume 145, pp. 21-42.

Werding, M., 2007. Versicherungsmathematisch korrekte Rentenabschlage für die gesetzliche Rentenversicherung. ifo Schnelldienst, pp. 19-32. 


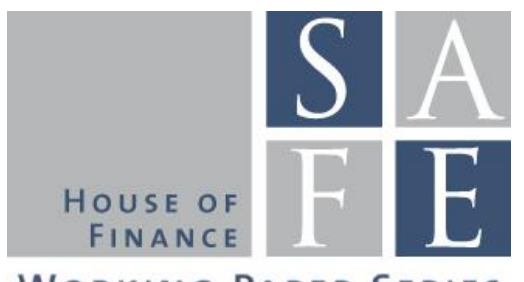

WORKING PAPER SERIES

\section{Recent Issues}

No. 220 Yangming Bao, Martin R. Goetz

No. 219 Andreas Hackethal - Christine Laudenbach - Steffen Meyer Annika Weber

No. 218 Florian Hoffmann, Roman Inderst, Marcus Opp

No. 217 Maddalena Davoli, Jia Hou

No. 216 Stefano Colonnello, Giuliano Curatola, Alessandro Gioffré

No. 215 Zsuzsa R. Huszár, Zorka Simon

No. 214 Edin Ibrocevic, Matthias Thiemann

No. 213 Klaus Gugler, Michael Weichselbaumer, Christine Zulehner

No. 212 Henning Hesse

No. 211 Thomas Mosk

No. 210 Darien Huang, Christian Schlag, Ivan Shaliastovich, Julian Thimme

No. 209 Eren Gürer, Alfons J. Weichenrieder

No. 208 Roberto Casarin, Michele Costola, Erdem Yenerdag
Local Peer Effects and Corporate Investment

Client Involvement in Expert Advice Antibiotics in Finance?

Only Time will Tell: A Theory of Deferred Compensation

Financial Literacy and Socialist Education: Lessons from the German Reunification

Pricing Sin Stocks: Ethical Preference vs. Risk Aversion

The Pricing Implications of the Oligopolistic Securities Lending Market: A Beneficial Owner Perspective

All Economic Ideas are Equal, but Some are more Equal than Others: A Differentiated Perspective on Macroprudential Ideas and their Implementation

Effects of Government Spending on Employment: Evidence from Winners and Runners-up in Procurement Auctions Incentive Effects from Write-down CoCo Bonds: An Empirical Analysis

Bargaining with a Bank

Volatility-of-Volatility Risk

Pro-rich Inflation in Europe: Implications for the Measurement of Inequality

Financial Bridges and Network Communities 